\title{
Antennal transcriptome analysis of olfactory genes and characterizations of odorant binding proteins in two woodwasps, Sirex noctilio and Sirex nitobei (Hymenoptera: Siricidae)
}

\author{
Bing Guo ${ }^{1 \dagger}$, Enhua Hao ${ }^{1 \dagger}$, Haili Qiao ${ }^{2}$, Jingzhen Wang ${ }^{1}$, Weiwei Wu' ${ }^{1}$ Jingjiang Zhou ${ }^{1}$ and Pengfei Lu ${ }^{1 *}$ (D)
}

\begin{abstract}
Background: The woodwasp Sirex noctilio Fabricius is a major quarantine pest worldwide that was first discovered in China in 2013 and mainly harms Pinus sylvestris var. mongolica Litv.. S. nitobei Matsumura is a native species in China and is closely related to $S$. noctilio. Recently, the two woodwasps species were found attacking the $P$. sylvestris var. mongolica Litv in succession. The olfactory system is the foundation of insect behavior. Olfactory genes were identified through antennal transcriptome analysis. The expression profiles odorant binding proteins (OBPs) were analyzed with RT-qPCR.
\end{abstract}

Results: From our transcriptome analysis, 16 OBPs, 7 chemosensory proteins (CSPs), 41 odorant receptors (ORs), 8 gustatory receptors (GRs), 13 ionotropic receptors (IRs), and one sensory neuron membrane protein (SNMP) were identified in S. noctilio, while 15 OBPs, 6 CSPs, 43 ORs, 10 GRs, 16 IRs, and 1 SNMP were identified in S. nitobei. Most of the olfactory genes identified in two species were homologous. However, some species-specific olfactory genes were identified from the antennal transcriptomes, including SnocOBP13, SnocCSP6, SnocOR26, SnocGR2, SnocIR7 in S. noctilio and SnitGR9, SnitGR11, SnitIR17 in S. nitobei. In total, 14 OBPS were expressed primarily in the antennae. SnocOBP9 and SnitOBP9, identified as PBP homologues, were sex-biased expression in two siricid, but with different pattern. SnocOBP11 and SnitOBP11 were highly expressed in antennae and clearly expressed in external genitalia. SnocOBP7 and SnitOBP7 were highly expressed in male genitalia. SnocOBP3 and SnocOBP10 were highly expressed in female genitalia and male heads, while SnitOBP3 and SnitOBP10 did not show obvious tissue bias.

\footnotetext{
* Correspondence: Ipengfei224@126.com

${ }^{\dagger}$ Bing Guo and Enhua Hao contributed equally to this work.

'The Key Laboratory for Silviculture and Conservation of the Ministry of Education, School of Forestry, Beijing Forestry University, 35 Qinghua Dong Road, Haidian District, Beijing 100083, People's Republic of China Full list of author information is available at the end of the article
}

C C The Author(s). 2021 Open Access This article is licensed under a Creative Commons Attribution 4.0 International License, which permits use, sharing, adaptation, distribution and reproduction in any medium or format, as long as you give appropriate credit to the original author(s) and the source, provide a link to the Creative Commons licence, and indicate if changes were made. The images or other third party material in this article are included in the article's Creative Commons licence, unless indicated otherwise in a credit line to the material. If material is not included in the article's Creative Commons licence and your intended use is not permitted by statutory regulation or exceeds the permitted use, you will need to obtain permission directly from the copyright holder. To view a copy of this licence, visit http://creativecommons.org/licenses/by/4.0/. The Creative Commons Public Domain Dedication waiver (http://creativecommons.org/publicdomain/zero/1.0/) applies to the data made available in this article, unless otherwise stated in a credit line to the data. 


\begin{abstract}
(Continued from previous page)
Conclusion: We analyzed 86 and 91 olfactory genes from S. noctilio and S. nitobei, respectively. Most of the olfactory genes identified were homologous, but also some species-specific olfactory genes were identified, which indicated the similarities and differences of the molecular mechanisms between the two closely-related species. Different expression in the antennae, external genitals or heads, exhibiting an obvious sex bias, suggested their different role in recognizing sex pheromones or plant volatiles. Species-specific expression for several OBPs genes may suggest that they strengthened or lost their original function during species differentiation, resulting in olfactory differences between the two species.
\end{abstract}

Keywords: Woodwasps, Transcriptome, Olfactory genes, Expression profiles

\section{Background}

Siricid woodwasps (Hymenoptera: Siricidae) are insects which mainly harm Pinus trees [1, 2]. As wood-boring insects, the woodwasps feed on wood during the larval period of their development. Adult woodwasps do not feed and only live for approximately a week [3, 4]. Female adults tend to attack stressed or weakened pines, where they lay eggs and inject toxic mucus and symbiotic fungus into the host $[5,6]$. The affected pine trees fall into decline and display symptoms such as resinosis, interior blue staining, premature senescence, reduced growth rates, and death [7].

Sirex noctilio Fabricius belongs to such woodwasps. It is native to Europe, Asia, and North Africa, and is attracted to dead or dying pines $[5,8,9]$. Due to increased human movement and trade, the woodwasp has spread to Oceania, Africa, North America, and South America and become a globally invasive insect species [10]. Because of the lack of competing species and natural predators, S. noctilio has had a major economic impact on various pines in invaded areas [10]. In August 2013, S. noctilio was first found in Heilongjiang and then in Liaoning, Jilin, and Inner Mongolia, China [11]. In contrast, S. nitobei Matsumura, a species closely related to S. noctilio, is native to China, Japan, and North Korea. It has posed a hazard on ancient and debilitated pines such as the Pinus tabuliformis in Xiangshan Park, Beijing, China [12] and is a significant threat to other pine species such as $P$. armandi and Larix spp. [13]. The morphology of the two species, S. noctilio and S. nitobei, are very similar. The difference between two woodwasps is the different colors of their abdomen and hindfoot. Recently, the two woodwasps species were reported attacking the $P$. sylvestris var. mongolica Litv. from June to September from 2016 to 2019 successively, in Jinbaotun town, Inner Mongolia Autonomous Region, China, within a year [14]. S. noctilio adults started to emerge in the field from late June to early September, subsequently, emerge peak of $S$. nitobei was found from same trees during late August and late September. Both of them are associated with the same fungal symbiont, Amylostereum areolatum in China [11].
In order to reduce the spread of and damage inflicted by woodwasps, it is important to develop effective detection tools to monitor their populations. Trap trees treated with herbicide or girdling have been used to monitor and survey $S$. noctilio populations $[9,15]$. The trap-tree method has been found to be effective but is expensive and difficult to implement. Kairomone (plant volatiles) lure traps are the most effective in areas where S. noctilio populations are large [16]. Pheromones are also commonly used to develop attractants, and several pheromone compounds for $S$. noctilio have been discovered $[17,18]$. In China, as a native species, $S$. nitobei remain relatively understudied and poorly understood, owing to their low abundance and habit of attacking only dead or highly stressed trees with little economic value. But, recently, $S$. nitobei has attracted attention due to its sympatric coexistence with the quarantine pest, $S$. noctilio. Field monitoring using attractants was carried out. Some traps with above mentioned lures for S. noctilio, either plant volatiles or pheromone, were also attractive to $S$. nitobei, but with different efficiency [19]. In a word, it is possible that chemical cues used by the two woodwasps are different to some extend.

Insects use their olfactory systems to sense odors and changes in the environment and thus, to adjust behaviors such as locating hosts for food, mating, and oviposition [20]. The antenna is the most important olfactory organ for recognition and sensing of pheromones or plant volatiles. There are multiple olfactory sensilla distributed on insect antennae, which house olfactory sensory neurons (OSNs). Odor molecules pass through pores on the sensilla and enter the sensillum lymph [21, 22]. It has been thought that odorant binding proteins (OBPs) and chemosensory proteins (CSPs) in the lymph can recognize, bind, and transport odor molecules. The OBP/CSP-odor molecule complexes then interact with chemosensory receptors, which are located in the dendritic membrane of OSNs [23, 24]. Chemosensory receptors are transmembrane proteins and include odorant receptors (ORs), ionotropic receptors (IRs), gustatory receptors (GRs), and sensory neuron membrane proteins (SNMPs). These receptors and OSNs convert the 
chemical signals into electrophysiological signals and transmit these signals to the central nervous system of insects through axons $[25,26]$. These signals are integrated in the insect brain to produce behavioral instructions for insects to respond accordingly [27]. At the same time, odor molecules are degraded by odorantdegrading enzymes (ODEs) [28, 29].

The objective of our study is to identify the chemosensory genes of the two species in order to characterize chemosensation in siricid species. We explored the woodwasp olfaction system, particularly, olfactory proteins and their expression profiles in antennae. We identified genes encoding olfactory proteins via analysis of the antennal transcriptomes of S. noctilio and S. nitobei and measured the transcript expression of important OBP genes in different tissues of both male and female adults of the two woodwasps using a quantitative realtime PCR method. Our study is the first description of differential expression profiles of OBPs between different tissues and between sexes for these two wasps. Taken together, our findings identified and compared olfactory genes in the two woodwasps based on antennal transcriptome analysis, and established a start point for further research on molecular mechanisms of olfactory system in symphyta woodwasps.

\section{Results}

Transcriptome sequencing and sequence assembly

Using transcriptome sequencing, a total of $174,174,820$ and 168,012,792 raw reads were obtained from male and female antennae, respectively, of $S$. noctilio, and a total of 165,394,906 and 164,334,008 raw reads were obtained from male and female antennae, respectively, of $S$. nitobei (Additional file 1, Table S1). By removing lowquality and trimmed reads less than $20 \mathrm{nt}$ in length, 168 , 575,526 and $164,447,898$ clean reads were obtained for male and female S. noctilio, respectively, and 161,515, 996 and 160,823,260 clean reads were obtained for male and female $S$. nitobei, respectively, to be used for de novo assembly (Additional file 1, Table S2). The clean reads from $S$. noctilio were assembled into 47,253 unigenes with a total length of $61,586,545$ base pairs (bp), an average length of $1303 \mathrm{bp}$, and a maximum length of $56,024 \mathrm{bp}$. The sequence length distribution analysis indicated that 16,625 unigenes (35.18\%) were longer than $1000 \mathrm{bp}$ (Additional file 1, Table S3). The clean reads from S. nitobei were assembled into 46,866 unigenes with a total length of 55,062,400 bp (Additional file 1, Table S4) and an average length of $1175 \mathrm{bp}$. The unigenes ranged from $201 \mathrm{bp}-39,567 \mathrm{bp}$ in length, and 13, 634 of the unigenes are $>1000 \mathrm{bp}$. The raw reads for $S$. noctilio and $S$. nitobei were deposited in the NCBI SRA database (the accession number of $S$. noctilio are from SAMN11338151 to SAMN11338156 and the accession number of $S$. nitobei are from SAMN11338569 to SAMN11338574).

\section{Homology analysis and gene ontology annotation}

In total, 20,053 unigenes from S. noctilio ( $42.44 \%$ of 47 , 253 unigenes) were annotated in at least one of the databases searched (Nr, Pfam, KOG, COG, Swiss-Prot, KEGG, eggNOG, and GO databases). Homology searches against the $\mathrm{Nr}$ database showed that the $S$. noctilio antennal transcriptome shared the greatest homology with sequences from Apis mellifera (13\%), followed by Nasonia vitripennis (11\%) and Harpegnathos saltator (10\%). For the S. nitobei transcriptome, 25,278 unigenes $(53.94 \%$ of 46,866 unigenes) were annotated in at least one of the databases. $\mathrm{Nr}$ database homology searches showed that the S. nitobei antennal transcriptome shared the greatest homology with sequences from $A$. mellifera (9.17\%), followed by $N$. vitripennis $(8.20 \%)$ and Megachile rotundata (7.27\%).

Among the 47,253 S. noctilio and 46,866 S. nitobei unigenes, 10,556 (22.3\%) and 13,487 (28.8\%), respectively, correspond to at least one GO term. GO annotation indicated that the distributions of GO terms in the unigenes were highly similar between the two species (Figs. 1 and 2). The similar result was found in the GO annotation between Helicoverpa armigera and $H$. assulta [30]. Within the biological process category, the most abundant terms were 'cellular process' 'single-organism process,' and 'metabolic process'. The 'cell' and 'cell part' were the most commonly represented of the cellular component terms. In the molecular function category, 'binding' and 'catalytic activity' were the most abundant terms.

Identification and analysis of chemosensory-related genes Odorant binding proteins (OBPs)

We identified 16 and 15 OBPs in the $S$. noctilio and $S$. nitobei antennal.

transcriptomes, respectively (Additional file 2, Table S1). Both S. noctilio and S. nitobei OBPs contained 15 full-length OBPs with complete open reading frames (ORFs) of at least $300 \mathrm{bp}$ and a signal peptide (except SnocOBP13). According to the OBP classification system, in both species, two OBPs (SnocOBP11 and Sni$t O B P 11)$ were found to be members of the Minus-C OBP subclass characterized by their lack of two cysteine residues $(\mathrm{C} 2$ and $\mathrm{C} 5)$. No Plus-C OBPs were found in either the $S$. noctilio or the $S$. nitobei transcriptome. Two woodwasp OBPs (SnocOBP9 and SnitOBP9) were homologous to PBPs of A. mellifera. These two OBPs are important because they may play roles in wasps' sexual behaviors. Five S. noctilio OBPs (SnocOBP3, SnocOBP4, SnocOBP10, SnocOBP14 and SnocOBP15) and five S. nitobei OBPs (SnitOBP3, SnitOBP4, SnitOBP10, SnitOBP14 and SnitOBP15) exhibited similarity with 


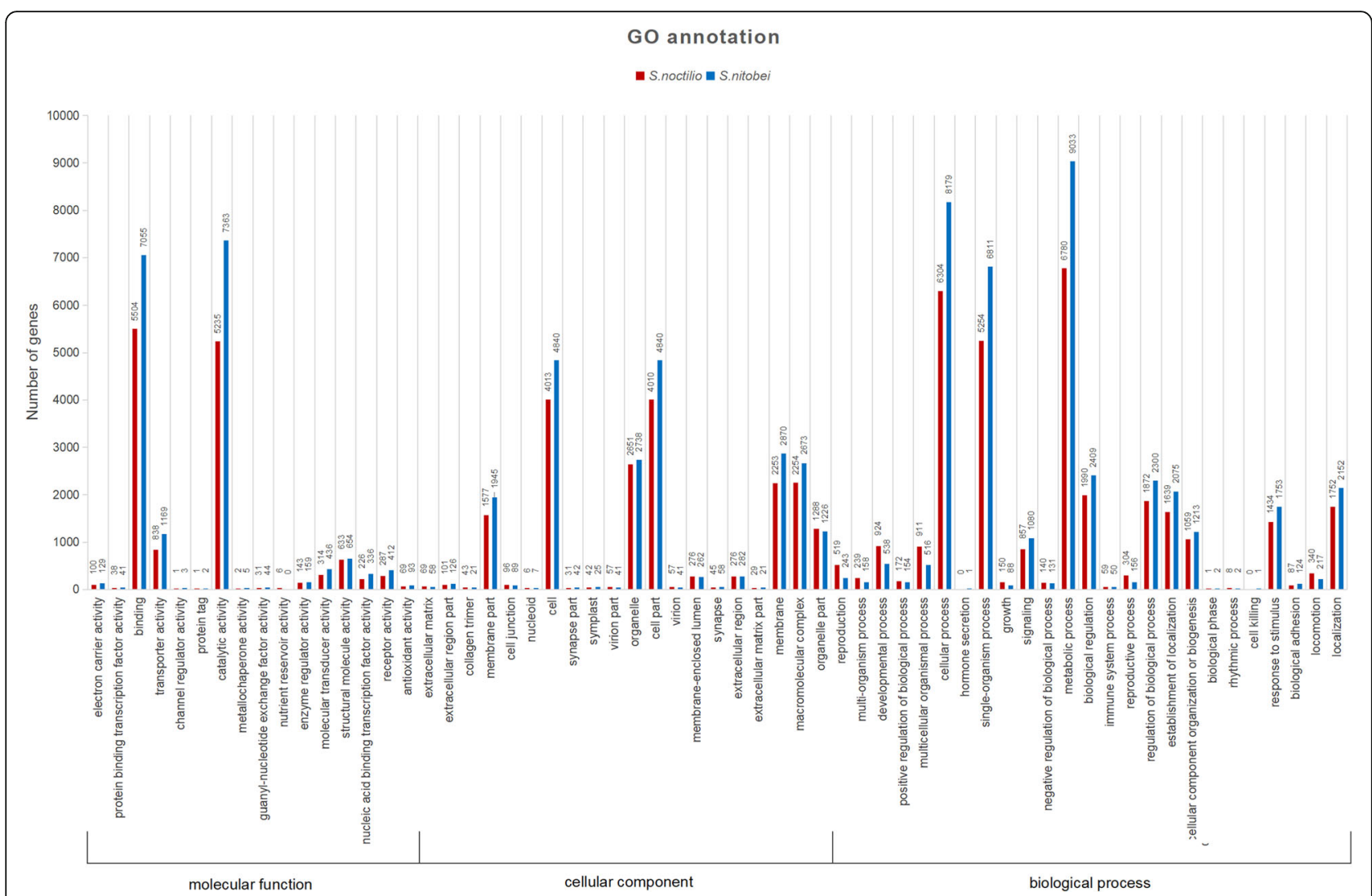

Fig. 1 Gene ontology (GO) classification showed by quantity of S. noctilio and S. nitobei unigenes obtained using the Blast2GO program

GOBPs of other insects by NCBI BLASTX. The cysteine sequence pattern of the full-length classic OBPs was found to be $\mathrm{C} 1-\mathrm{X}_{26-32}-\mathrm{C} 2-\mathrm{X}_{3}-\mathrm{C} 3-\mathrm{X}_{36-42}-\mathrm{C} 4-\mathrm{X}_{8-}$ ${ }_{12}-\mathrm{C} 5-\mathrm{X}_{8}$-C6 (Additional file 3 ). We found $13 \mathrm{Sno}$ $c O B P \mathrm{~s}$ and 14 SnitOBPs with expression values greater than 1 FPKM, while 6 SnocOBPs and 7 Sni$t O B P$ s exhibited expression values greater than 100 FPKM, indicating high expression of these OBPs in the antennae.

Construction of a phylogenetic tree was used to compare insect OBP protein sequences from members of the Hymenoptera, Diptera, and Lepidoptera (Fig. 3). According to the OBP phylogenetic tree, most SnocOBPs and SnitOBPs sequences clustered together. SnocOBP13 was unique to $S$. noctilio and did not cluster with other OBPs. No homologous gene had been found in S. nitobei. However, the FPKM value of SnocOBP13 was less than 0.001 in the transcriptome dataset, so it was hardly expressed in antennae. With a 1.00 bootstrap support value, the PBP lineages contained SnocOBP9, SnitOBP9, and other Hymenopteran PBPs, which further confirmed that the two OBPs could be PBPs. OBP4, OBP7, and OBP10 of both woodwasps were clustered in the GOBP lineages with $0.75,1.00$, and 1.00 bootstrap support values, respectively.

\section{Chemosensory proteins (CSPs)}

We identified 7 SnocCSPs and 6 SnitCSPs in the antennal transcriptomes of the two woodwasp species (Additional file 2, Table S2). Among all CSPs, 5 CSPs in $S$. noctilio and 4 in S. nitobei were full-length CSPs with complete ORFs, signal peptides, and a cysteine sequence pattern of $\mathrm{C} 1-\mathrm{X}_{5-8}-\mathrm{C} 2-\mathrm{X}_{18}-\mathrm{C} 3-\mathrm{X}_{2}-\mathrm{C} 4$ (Additional file 4). The expression values (FPKM) of 4 SnocCSPs and 5 SnitCSPs were greater than 1 , while 1 SnocCSP and 3 SnitCSPs displayed expression values greater than 100, indicating that these genes were highly expressed in the woodwasp antennae.

In the phylogenetic tree (Fig. 4), most SnocCSPs and SnitCSPs were clustered with other Hymenopteran CSPs. The homologous SnocCSP6 was not found in $S$. nitobei. The S. noctilio specific SnocCSP6 was clustered with DmelCSP2 in Drosophila melanogaster with 0.54 bootstrap support value. The FPKM value of SnocCSP6 was 0.325 , so its expression was very low in $S$. noctilio antennae.

\section{Odorant receptors (ORs)}

We identified 41 and 43 ORs in the S. noctilio and $S$. nitobei antennal transcriptomes, respectively (Additional file 2, Table S3). Two woodwasp OR transcripts were 


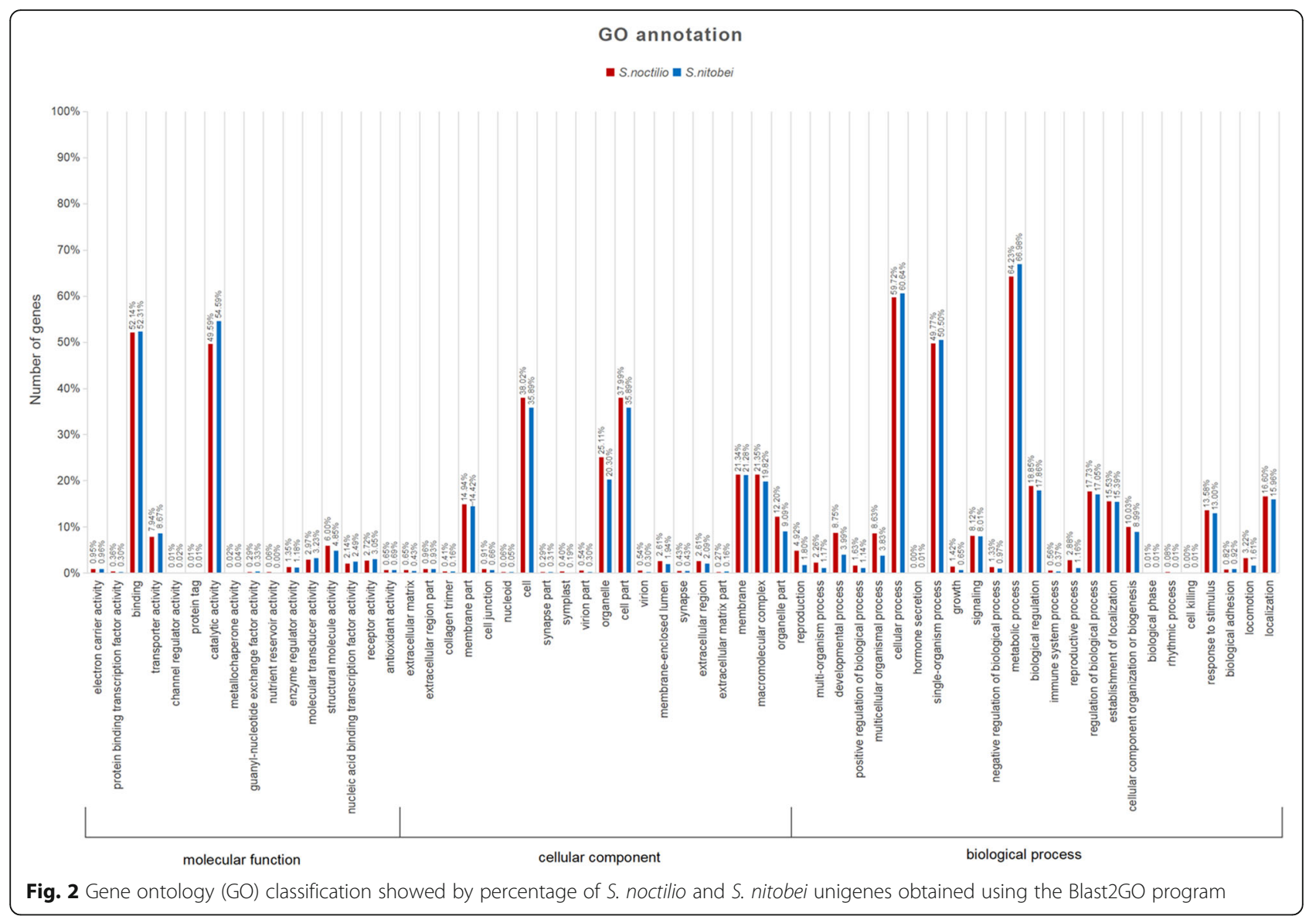

identified as odorant co-receptors, and designated as SnocORco and SnitORco, respectively. Compared to traditional odor receptors, ORco is highly conserved, and its homology among insects can reach 50-99\%. Amino acid sequence analysis revealed a highly conserved region at the end of the ORco sequence [31].

In total, 28 SnocORs and 30 SnitORs contained complete ORFs with more 350 amino acids, indicating that they were nearly full-length. Using the TMHMM Server, we found that 4 full-length SnocORs (SnocORco, SnocOR5, SnocOR8, and SnocOR30) and 3 full-length SnitORs (SnitORco, SnitOR8, and SnitOR30) possessed 7 transmembrane helices. No transmembrane helices were predicted in SnocOR32, SnocOR33, SnitOR31, and SnitOR32, which may be due to short fragments and incomplete reading frames. Four ORs (SnocOR18, SnocOR30, SnitOR18 and SnitOR30) displayed a $>10$-fold difference in expression between males and females, suggesting that they may play a role in identifying genderrelated odors.

Most SnocORs and SnitORs were clustered together in the phylogenetic tree (Fig. 5). Two special lineages were identified in the tree. The ORco lineage contained SnocORco and SnitORco (1.00 bootstrap support value), which further confirmed that these two ORs were ORcos. And the two ORcos were clustered with the honey bee ORco AmelOR2 [32] and other Hymenoptera ORco, suggesting they could function as a complex with other ORs in the woodwasps as the ORcos in other insects. The sirex-specific lineages contained SnocOR9, SnocOR12, SnocOR17, SnocOR20, SnocOR22a, SnocOR22b, SnocOR23 in S. noctilio and SnitOR1a, SnitOR1b, SnitOR9, SnitOR12, SnitOR17, SnitOR20a, SnitOR20b, SnitOR22a, SnitOR22b, SnitOR23 in S. nitobei. As to not-sirex-specific lineages, most of the OR genes identified in two species were homologous, but SnocOR26 is a species-specific OR genes in S. noctilio.

\section{Sensory neuron membrane proteins (SNMPs)}

We identified one SNMP in S. noctilio (SnocSNMP1) and one in S. nitobei (SnitSNMP1) (Additional file 2, Table S4). SNMP2 could not be identified in both woodwasps species. SnocSNMP1 and SnitSNMP1 were predicted to possess 2 transmembrane regions, which may indicate that SnocSNMP1 and SnitSNMP1 were full-length genes. The expression values (FPKM) for SnocSNMP1 and SnitSNMP1 were both found to be 


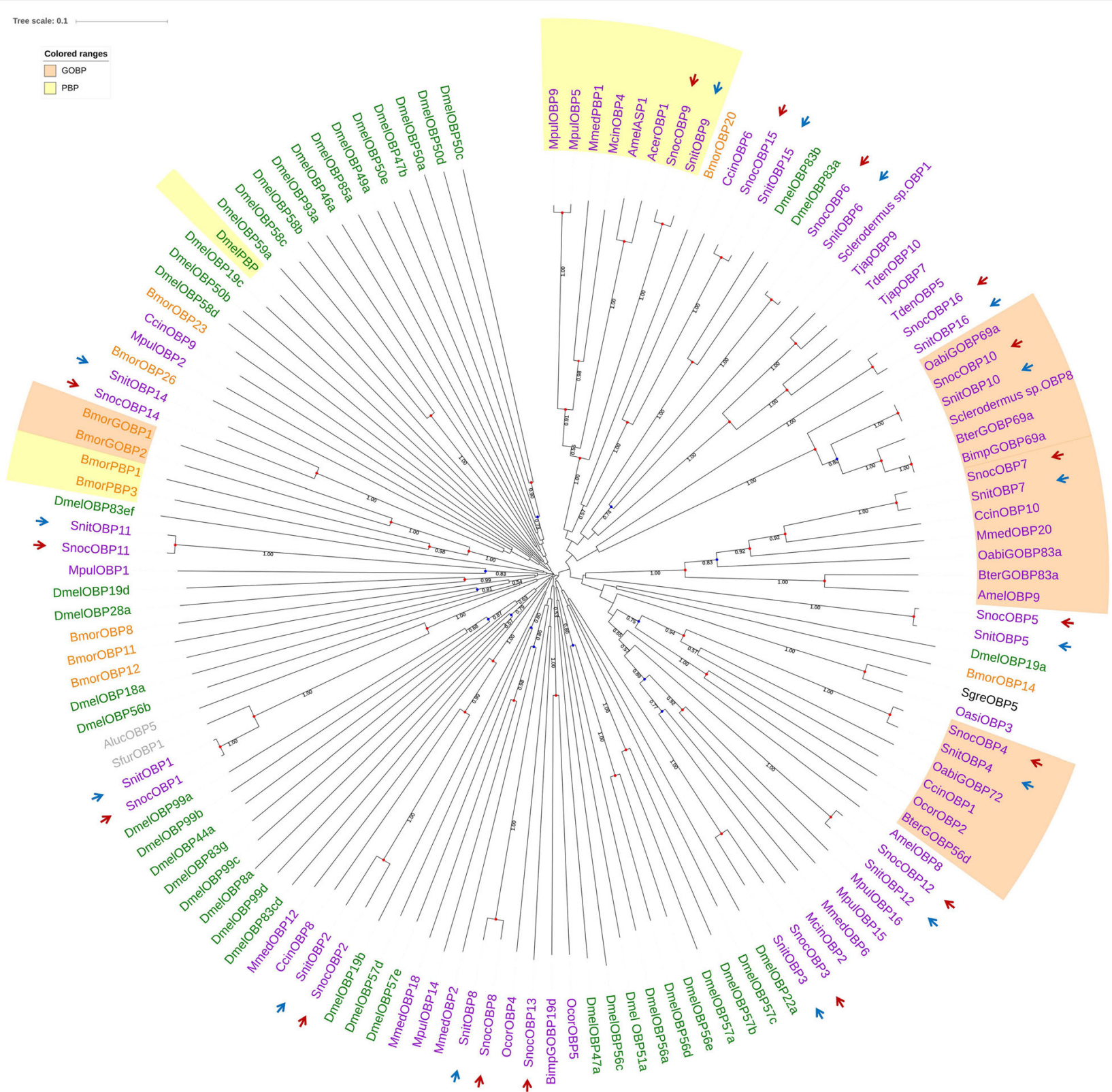

Fig. 3 Candidate odorant binding proteins (OBPs) of Hymenoptera (purple), Diptera (green), Hemiptera (gray), Orthoptera (black) and Lepidoptera (orange) were included in a neighbor-joining phylogenetic tree. The PBP and GOBP lineages are labelled in yellow and orange, respectively. SnocOBPs and SnitOBPs are indicated with red and blue arrows, respectively

greater than 100, indicating that Sirex SNMPs are highly expressed in the antennae.

SNMPs are considered to be highly conserved in holometabolous insects, but SNMP1 and SNMP2, which are members of different subfamilies, clustered separately in disparate lineages. In our phylogenetic tree, SnocSNMP1 and SnitSNMP1 clustered in the SNMP1 lineage with a bootstrap support value of 1.00 (Fig. 6).

\section{Gustatory receptors (GRs)}

We identified 8 and 10 GRs in the S. noctilio and S. nitobei antennal transcriptomes, respectively (Additional file 2, Table S5). Using BLASTX sequence alignment, we found that 2 SnocGRs and 7 SnitGRs were clustered with the GRs for sugar taste, and most were found to be trehalose receptors. No Sirex GRs clustered in the bitter taste lineages.

In the phylogenetic tree (Fig. 7) of GR sequences, there were two sugar taste lineages, three bitter taste lineages 


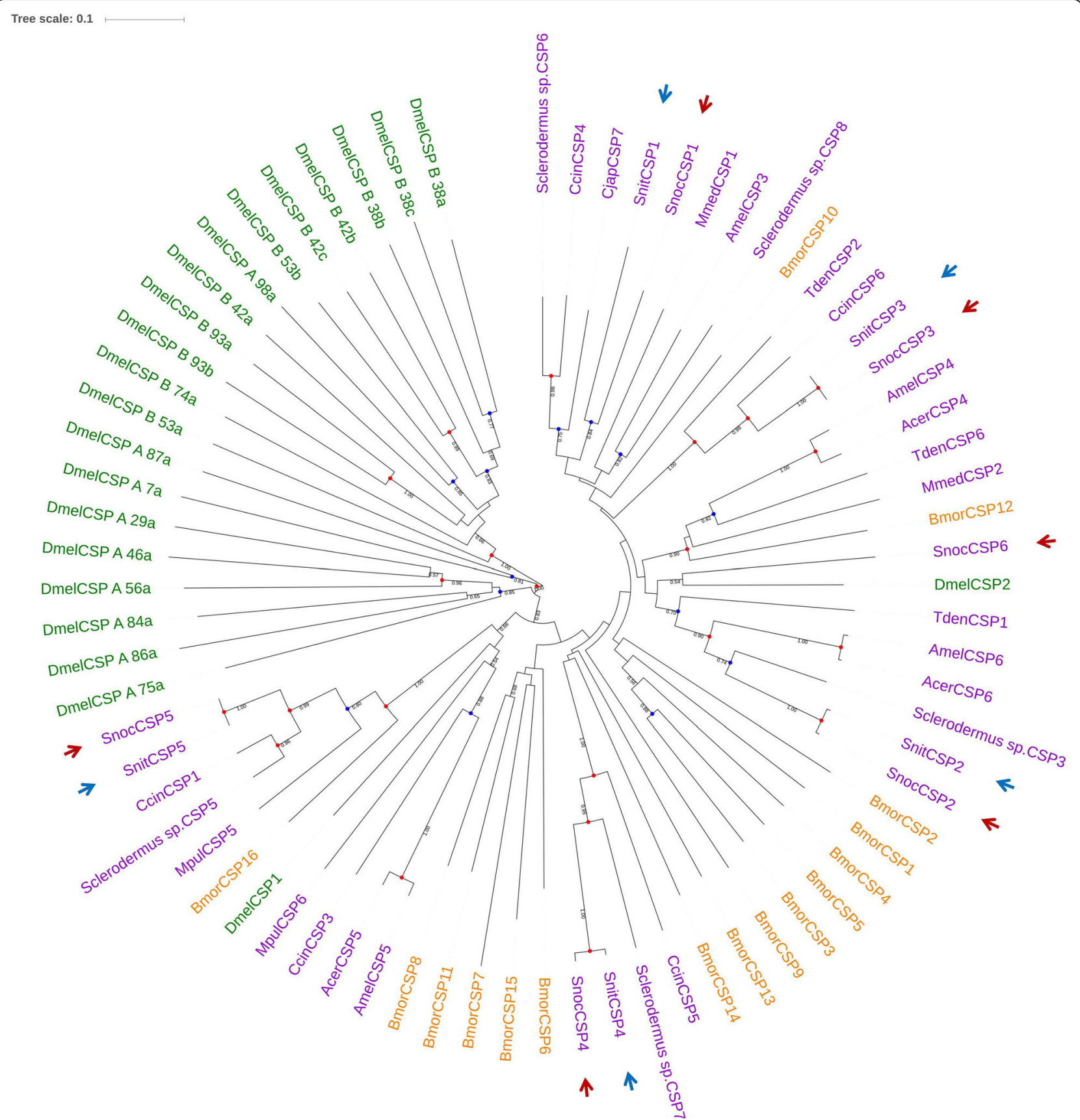

Fig. 4 Candidate chemosensory proteins (CSPs) of Hymenoptera (purple), Diptera (green), and Lepidoptera (orange) are displayed in a neighborjoining phylogenetic tree. SnocCSPs and SnitCSPs are marked with red and blue arrows, respectively

and one carbon dioxide receptor lineages. Most Sirex GRs exhibited homology to sugar taste receptors, and one SnocGR and 3 SnitGRs clustered in the sugar taste lineages. SnocGR5 and SnitGR5a were homologous genes and they clustered with CcinGR64f for sugar taste in Cephus cinctus with 0.59 bootstrap support value. SnitGR11 clustered with TcorGR for trehalose in Trachymyrmex cornetzi with 1.00 bootstrap support value and SnitGR9 clustered with OabiGR43a for sugar taste in Orussus abietinus with 0.60 bootstrap support value. These two GR had not found homologous genes in S.noctilio. SnocGR3 and SnitGR3 were homologous genes and they clustered with ArosGr22 for carbon dioxide receptor in Cephus cinctus with 0.59 bootstrap support value. SnocGR2 clustered with CcinGR24 for trehalose in Trachymyrmex cornetzi with 1.00 bootstrap support value. As to not-sugar taste, not-bitter taste or not-carbon dioxide recepto lineages, most of the GR 


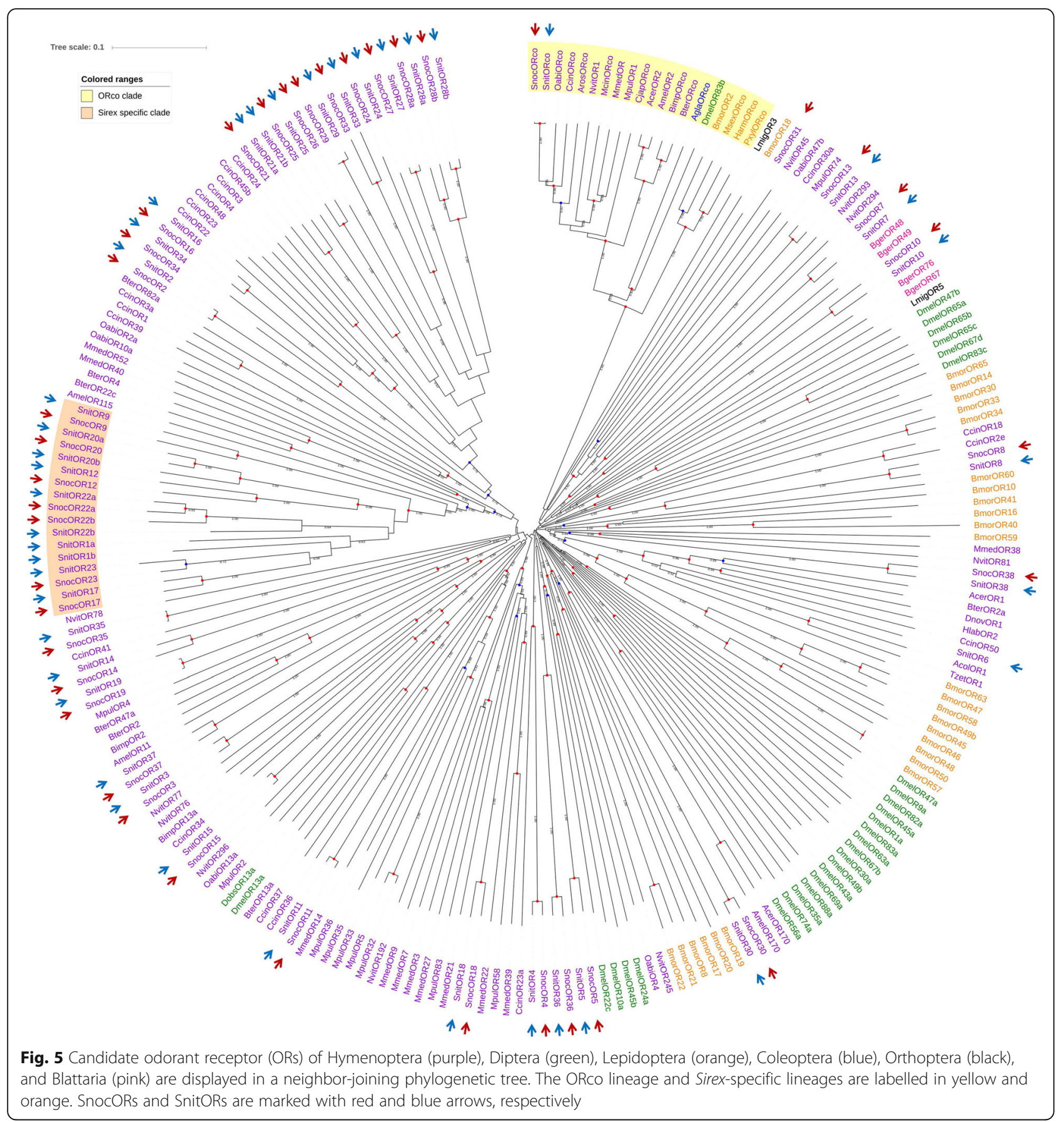

genes identified in two species were homologous, but SnitGR8 and SnitGR10 was specific to S. nitobei.

\section{lonotropic receptors (IRs)}

We identified 13 and 16 IRs in the S. noctilio and S. nitobei antennal transcriptomes, respectively (Additional file 2, Table S6). The expression values (FPKM) of 4 SnocIRs and 11 SnitIRs were greater than 1. Of these, SnocIR6 and SnitIR6 had the greatest expression in the antennal transcriptome with FPKM values of 16.359 and 21.583 respectively, which suggested that IR6 may play a major role in two woodwasps.

Previous studies have indicated that IR8a and IR25a are the co-receptors of IRs [33-35]. In our phylogenetic tree (Fig. 8), SnocIR6 and SnitIR6 clustered in the coreceptor IR8a lineages with a bootstrap support value of 1.00 , while SnocIR4 and SnitIR4 clustered in the coreceptor IR25a lineages with a bootstrap support value of 1.00. IR6 and IR4 exhibited a high expression in Sirex transcriptomes, which may indicate that the IRs are co- 


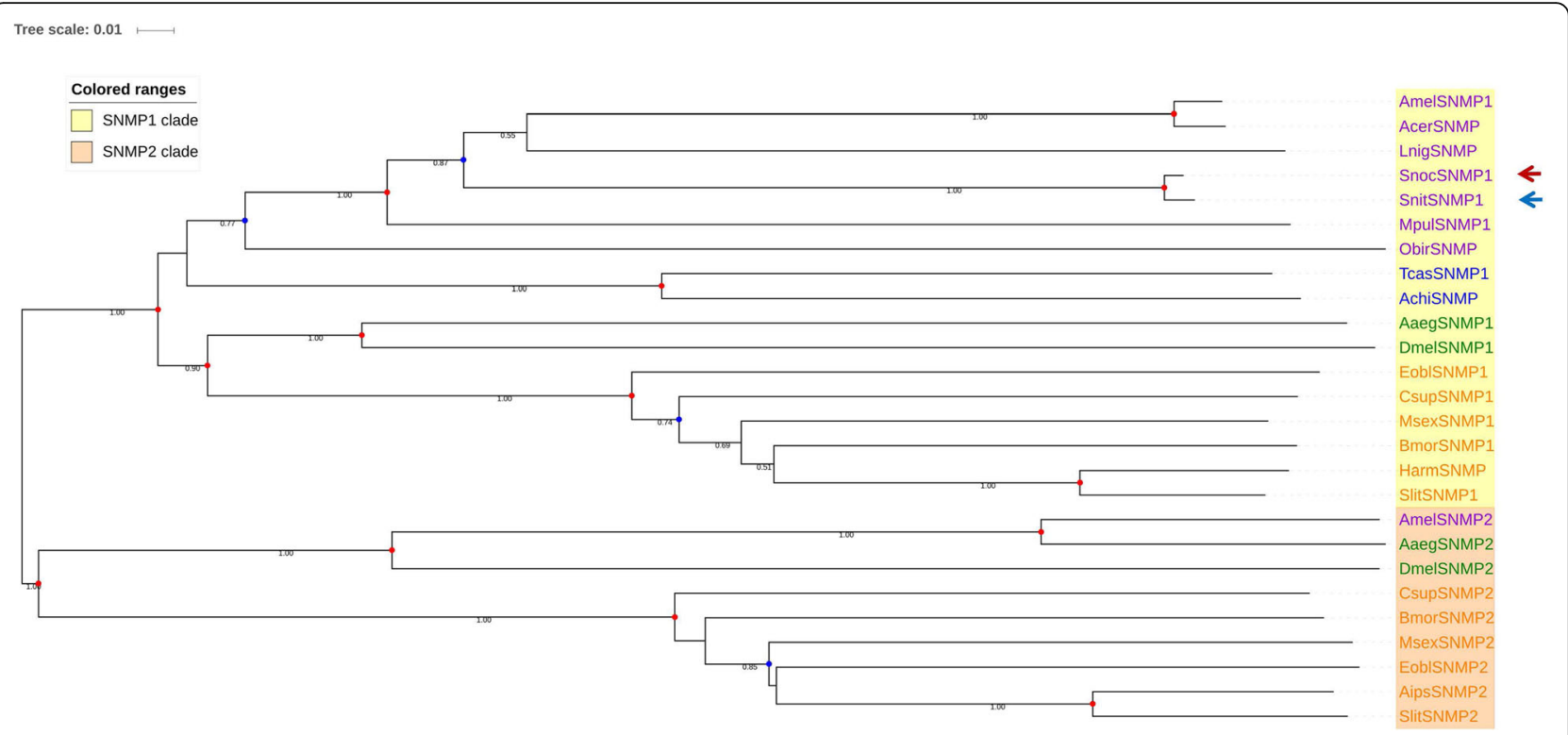

Fig. 6 Candidate sensory neuron membrane proteins (SNMPs) of Hymenoptera (purple), Diptera (green), Lepidoptera (orange), and Coleoptera (blue) are displayed in a neighbor-joining phylogenetic tree. SnocSNMP1 and SnitSNMP1 are marked with red and blue arrows, respectively

receptors for IRs. Similarly, two IRco genes were found in $M$. mediator [36], while only one IR25a homolog was found in the wasp species C. cunea and M. pulchricornis. Additionally, two pairs of NMDA receptors (N-methylD-aspartic acid receptor) were found in the phylogenetic tree (SnocIR10, SnocIR12, SnitIR10 and SnitIR12). Among not-IRco and not-NMDA lineages, most of the IR genes identified in two species were homologous, but SnocIR7 and SnitIR17 were specific to S. noctilio and S. nitobei, respectively.

\section{Clusters of olfactory system genes in S. noctilio and S. nitobei}

We used the olfactory genes of the two woodwasp species to build multiple phylogenetic trees (Fig. 9). In our phylogenetic tree, most of the S. noctilio and S. nitobei olfactory genes clustered together. Additionally, we found that most of the S. noctilio and S. nitobei olfactory genes were homologous, supporting the close relationship between the two species. We also found that there were some species-specific genes such as SnocOBP13, SnocCSP6, SnocOR26, SnocGR2, SnocIR7 in S. noctilio and SnitGR9, SnitGR11, SnitIR17 in S. nitobei.

According to the analysis of heat map (Fig. 9) and significant expression of FPKM (Additional file 5), some homologous genes, including OBP3, OBP8, OBP9, OBP15, CSP2, ORco, OR1, OR13, OR17, OR31, OR34, OR36, OR37, GR4, IR9, IR10 and IR13, have different expression profiles between two siricids. Among them, OR13, OR31 and OR36 were highly expressed in S. noctilio and other olfactory genes were highly expressed in $S$. nitobei (Additional file 5). In the same way, some of the homologous genes were expressed differently between males and females, such as OR18 and OR30, were both significantly expressed in male antennae of two siricids (Additional file 5).

\section{Fluorescent quantitative real-time PCR}

To verify OBPs expression in the antennae and characterize the expression profiles of OBPs in 4 chemosensory tissues (antennae, legs, heads, and externalia), 10 SnocOBPs and 10 SnitOBPs with high FPKM values were selected for fluorescent quantitative real-time PCR (Figs. 10 and 11). Primers for OBPs and for an internal reference gene ( $\beta$-tubulin) were listed in the Additional file 6.

We compared the results of FPKM value and RTqPCR, and found that most OBPs expression trends were the same in male and female antennae, further proving the accuracy of transcriptome data. Most OBPs were expressed mainly in the antennae of the two woodwasps. The observed high expression in the antennae suggested that the OBPs may play a role in binding and transporting odor signals in antennae. In addition, species-specific, tissue or sex-biased expression were also observed as follow.

Firstly, significant species-specific expression was observed for many OBP genes, especially those not greatly expressed in the antennae, including $O B P 3$ and $O B P 10$. SnocOBP3 was primarily expressed in the genitalia of female S. noctilio. SnocOBP10 was mainly expressed in male heads, while SnitOBP3 and SnitOBP10 did not show obvious tissue bias due to low expression levels 


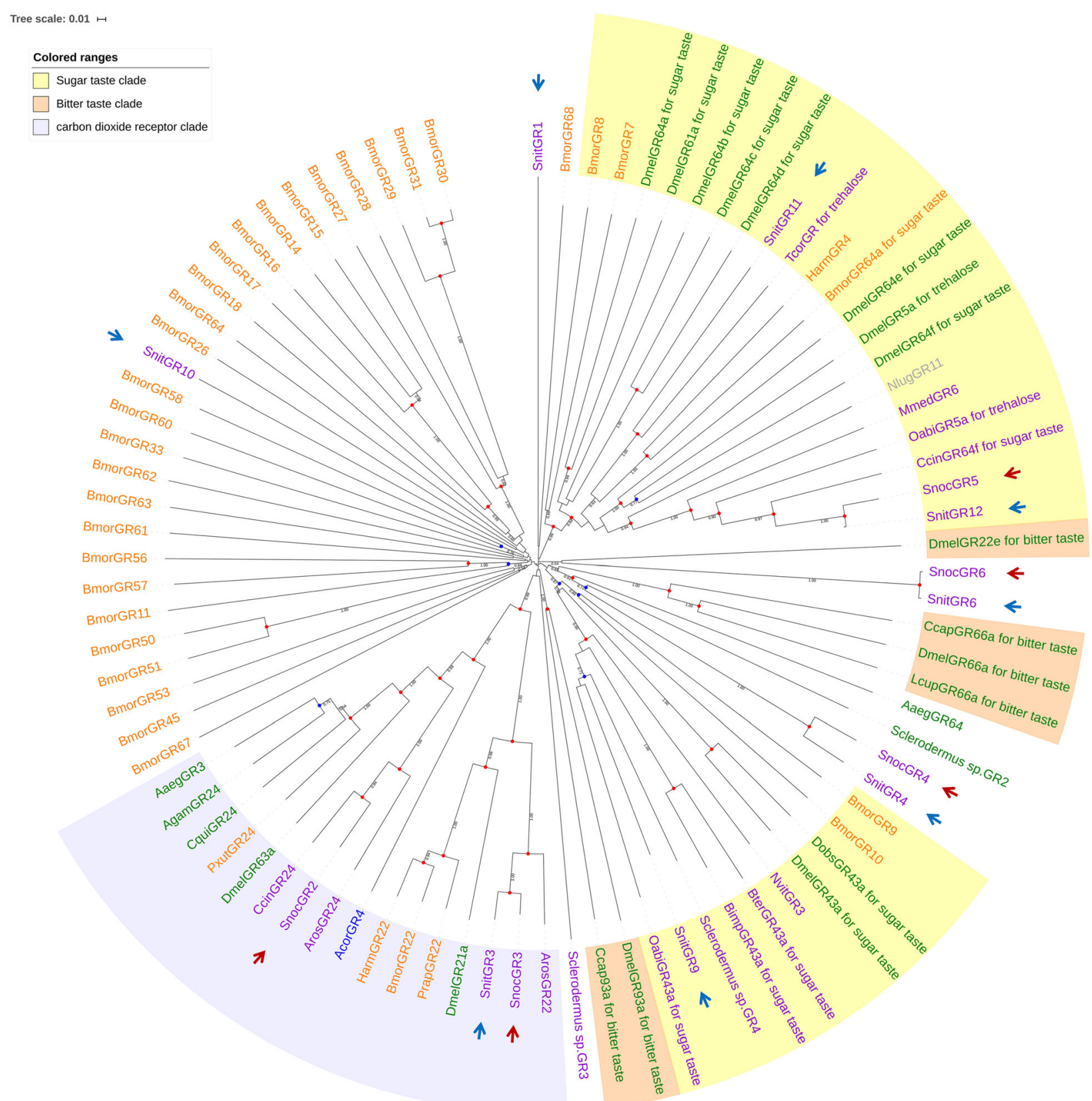

Fig. 7 Candidate gustatory receptors (GRs) of Hymenoptera (purple), Diptera (green), Lepidoptera (orange), Coleoptera (blue), and Hemiptera (gray) are displayed in a neighbor-joining phylogenetic tree. The sugar taste lineages and bitter taste lineages have been labelled. SnocGRs and SnitGRs are marked with red and blue arrows, respectively

(Fig. 11). In addition, we also found that some homologous genes mainly expressed in the antennae differ in their expression profiles between the two species. For example, SnocOBP9 showed a weak expression bias between two sexes but the difference was not significant $(P>0.05)$, however, SnitOBP9 had a significantly differential expression between two sexes $(P<0.05)$, which had a higher expression in female antennae. The differential expression of these homologous genes may suggest that they strengthened or lost their original function during species differentiation, resulting in olfactory differences between the two species.

Secondly, significant tissue-biased expression was observed for many OBP genes. Most OBPs, including OBP4, OBP6, OBP8, OBP9, OBP12 and OBP15, were primarily expressed in antennae of two siricids (Fig. 10). 


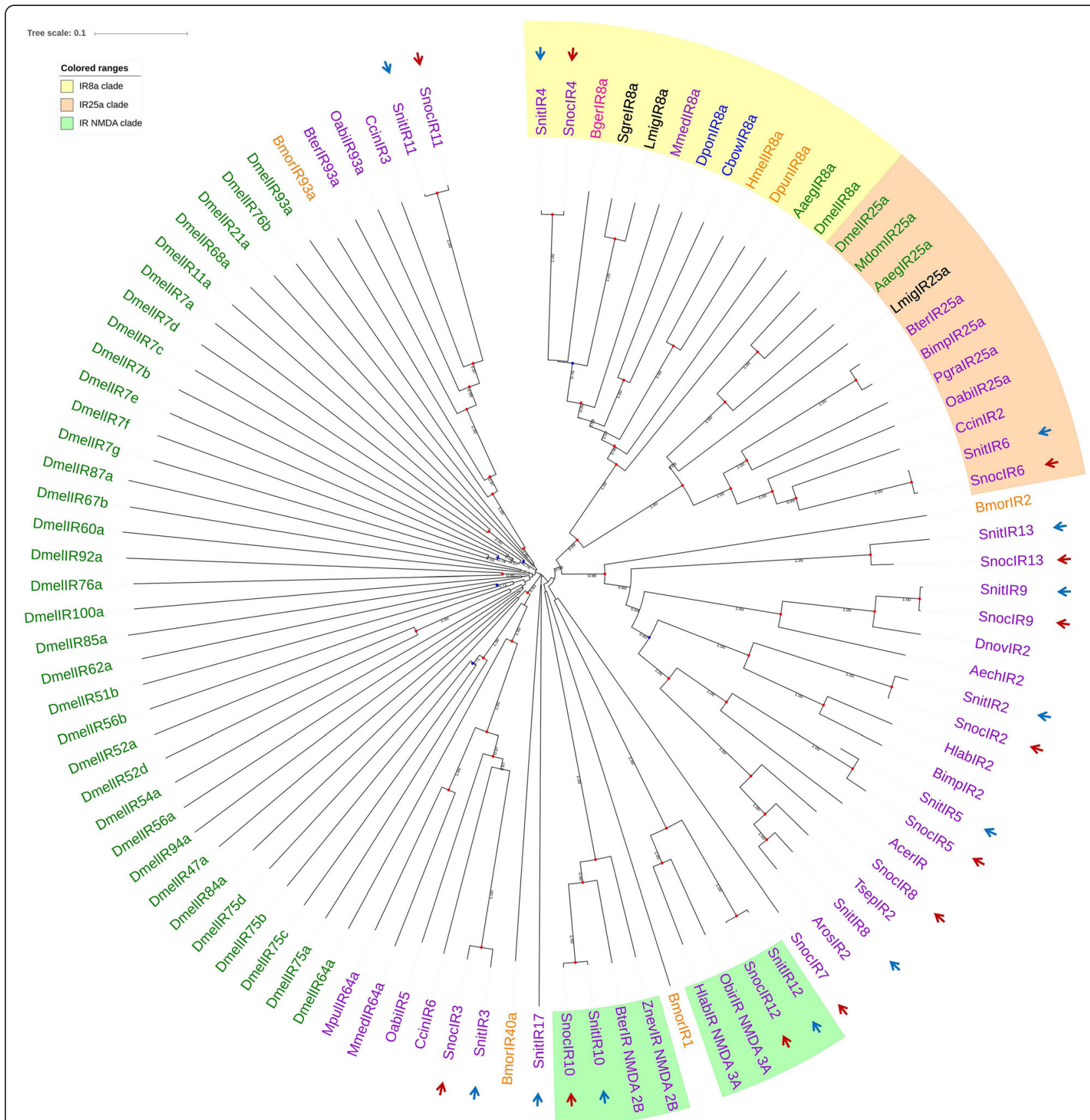

Fig. 8 Candidate ionotropic receptors (IRs) of Hymenoptera (purple), Diptera (green), Lepidoptera (orange), Coleoptera (blue), Blattaria (pink) and Orthoptera (black) are displayed in a neighbor-joining phylogenetic tree. The IR8a lineage, IR25a lineage, and NMDA lineages have been labelled. SnocIRs and SnitIRs are marked with red and blue arrows, respectively

For both SnocOBP9 and SnitOBP9 that were identified as $P B P$ homologues, we observed high expression in antennae and no detectible expression in the other organs. Additionally, SnocOBP11 and SnitOBP11 were more highly expressed in the female external genitalia and male antennae when compared to the male external genitalia and female antennae (Fig. 10). High expression of SnocOBP7 and SnitOBP7 was detected in male externalia (Fig. 11).

Finally, significant sex-biased expression was observed for many OBP genes, including almost all 10 SnocOBPs and 10 SnitOBPs with high FPKM values, which were sex-biased expression either in antennae or external genitalia (Figs. 10 and 11). This sex bias may denote 


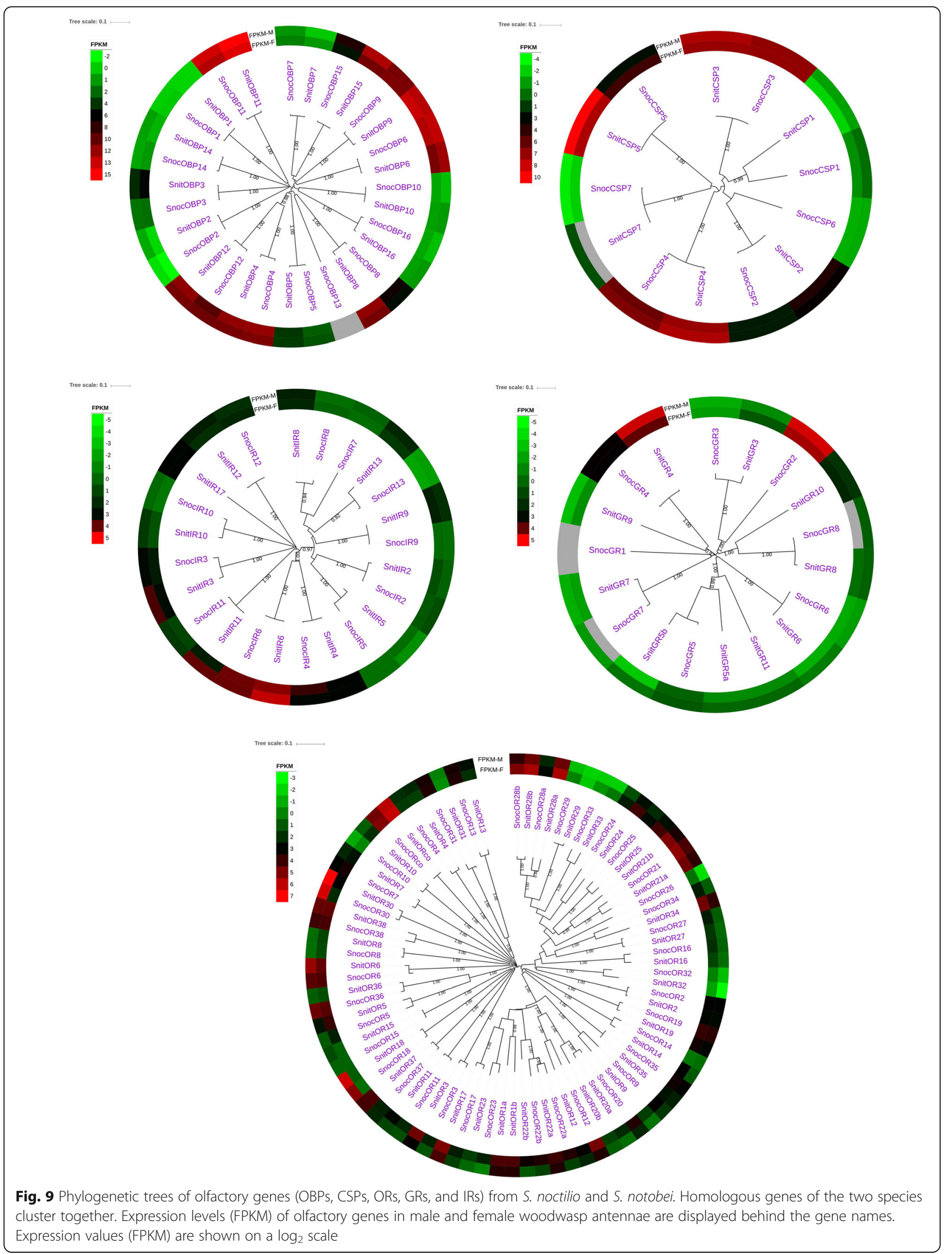




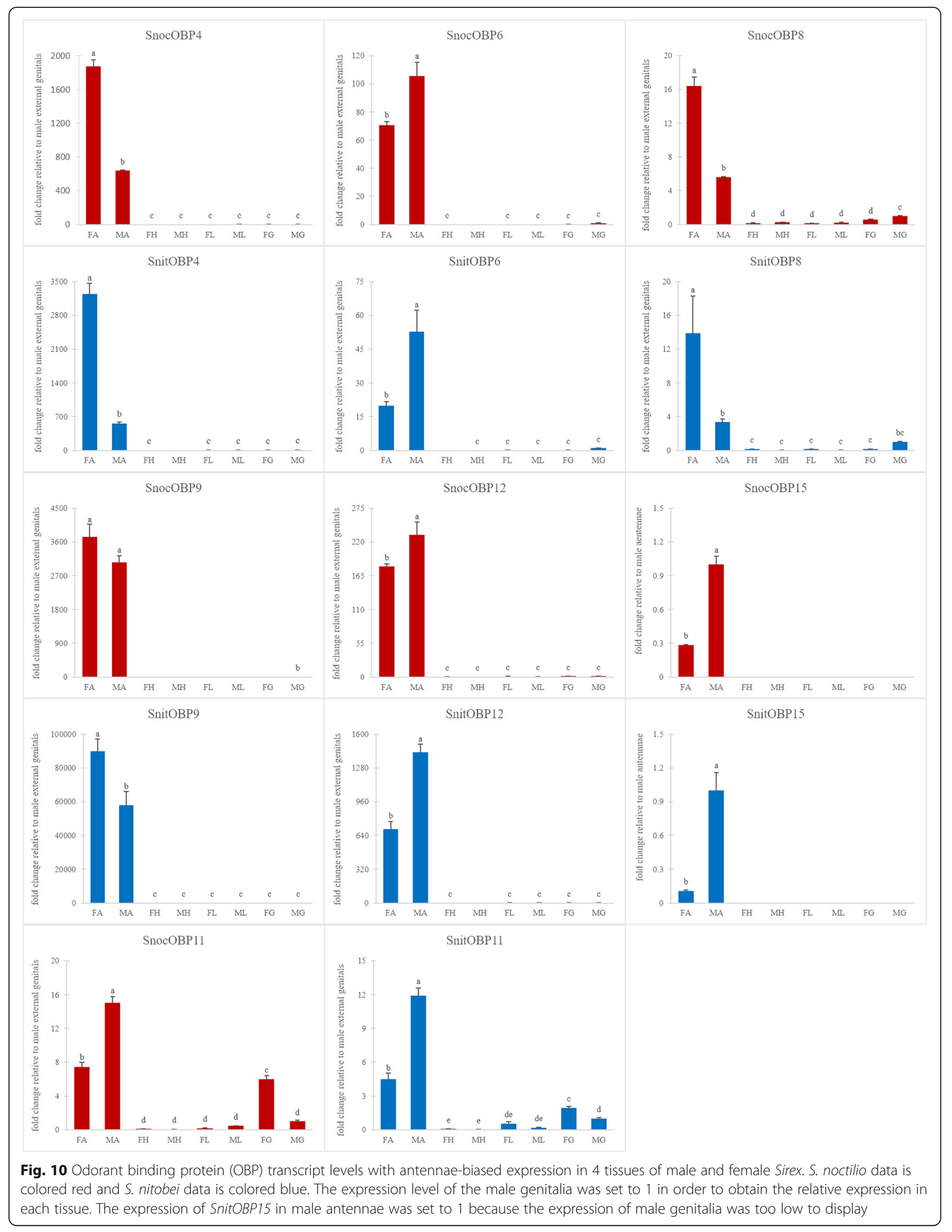




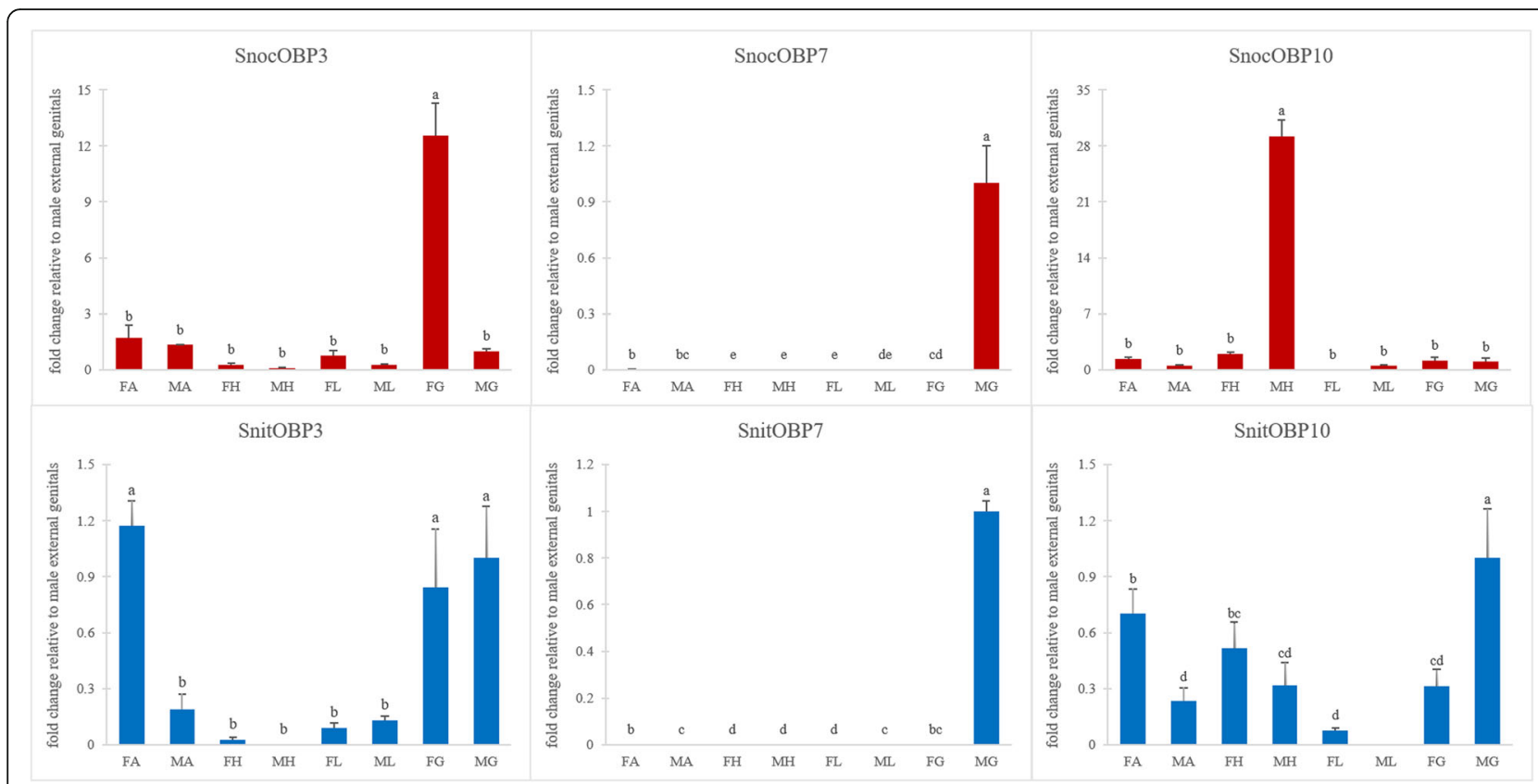

Fig. 11 Odorant binding protein (OBP) transcript levels with head-biased, genital-biased or unbiased expression in 4 tissues of male and female siricids. S. noctilio data is colored red and S. nitobei data is colored blue. The expression level in male genitalia was set to 1 in order to display the relative expression in each tissue

different functions of these OBPs between males and females, such as the perception of the opposite sex or oviposition behavior.

\section{Discussion}

\section{Comparison of olfactory genes in two siricids}

Temporal and spatial niches divergence led to no apparent competitive pressures between the two species on $P$. sylvestris var. mongolica Litv. in China [14]. In recent study in 2019, we found S. noctilio and $S$. nitobei can share similar attractants ( $\alpha$-pinene, $\beta$-pinene, 3 -carene, camphene) in the field, consistent with that they recognized common host plants [19]. From our transcriptome analysis, most of the olfactory genes identified in two species were homologous between the two species, supporting their close relationship.

On the other hand, trapping experiment also showed although these attractants were attractive to both species, but with different efficiency with each other. It is possible that chemical cues used by the two woodwasps are different to some extend. From our transcriptome analysis, some species-specific olfactory genes were identified from the antennal transcriptomes, including SnocOBP13, SnocCSP6, SnocOR26, SnocGR2, SnocIR7 in S. noctilio and SnitGR9, SnitGR11, SnitIR17 in S. nitobei. In addition, some homologous genes, including OBP3, OBP8, OBP9, OBP15, CSP2, ORco, OR1, OR13, OR17, OR31, OR34, OR36, OR37, GR4, IR9, IR10 and IR13, were significantly different between the two siricids. Species-bias expression in olfactory genes between the two species will be a study emphasis in further research.

By studying these olfactory genes, the molecular mechanism of the olfactory difference between the two species can be better elucidated.

\section{Number of OBPs varies greatly among different species}

Compared with OBPs of model species, the numbers of OBPs encoded in the genomes of siricids (16 in S. noctilio and 15 in $S$. nitobei) were less than those in D. melanogaster (51 OBPs), Anopheles gambiae (57 OBPs), B. mori (44 OBPs), and $N$. vitripennis (82 OBPs) [37-42]. In Hymenoptera, there are species with more OBPs than the siricids, such as those of Aenasius bambawalei (54 OBPs), while there are also species with fewer OBPs than the siricids, such as Osmia cornuta (6 OBPs) and Microplitis mediator (7 OBPs) [43-46]. A. mellifera possesses a similar set of these genes, consisting of only 21 OBPs. This suggests differences in the modalities of olfactory discrimination for different insect species.

One possibility is that insects with less OBPs has lower discrimination capabilities than other insects with more OBPs. Some researchers suggest that more singular and closed environments are associated with less lineagespecific OBP expansion such as 7 OBPs of Ceratosolen solmsi and 5 OBPs of Pediculus humanus humanus [45, 47]. This may also be a reason why the number of OBPs in the sirisids is small. S. noctilio and S. nitobei live in 
pure forests or mixed coniferous forests and thus are more likely to receive plant volatiles or interspecies pheromone substances from a closed environment.

In S. noctilio and S. nitobei, most OBPs are orthologous, supporting the previous reports that the evolution of OBPs is mainly driven by lineage-specific amplification, with few distinct homologues in non-relative species $[37,38,48]$. The siricid OBPs also display strong homology with other Hymenopteran species and have low similarity with OBPs in other insects such as D. melanogaster and B. mori, further illustrating the evolutionary relationship of OBPs in insect specialization.

\section{Special subfamilies of OBPs}

We did not uncover any Plus-C OBPs in the transcriptomes of S. noctilio and S. nitobei. Plus-C OBPs were found in Lepidoptera (B. mori), Diptera (D. melanogaster), Coleoptera (Anoplophora chinensis), but were not found in existing Hymenoptera genomes or transcriptomes [49]. For example, Plus-C OBPs were not found in the genomes of Hymenoptera such as A. mellifera and $N$. vitripennis [42]. This finding suggests that the Plus- $C$ subtype is rare or even absent in Hymenoptera and has had no influence on the olfactory recognition in Hymenoptera. However, the Minus-C subtype has been widely observed in Hymenopterans. For example, AmelOBP14-21 and NvitOBP27, $-38,-56$, and $-58-62$ are Minus-C OBPs. We identified one Minus-C OBP in each S. noctilio and S. nitobei. These two Minus-C OBPs were not homologous with the Minus-C OBPs of A. mellifera and N. vitripennis, but were homologous to a Classic OBP of Meteorus pulchricornis, MpulOBP1 [50]. It is reasonable that the minus-C OBPs of the wasps could share a common evolutionary ancestor of a classic OBPs as speculated previously in A. mellifera that the eight $A$. mellifera minus-C OBPs and AmelOBP13 shared a common evolutionary ancestor [39]. It can be inferred that the Minus-C OBP originated from a classic OBP that lost two cysteine residues during evolution, rather than having evolved from a Minus- $\mathrm{C}$ OBP of another species. The expression values of the two Minus-C OBPs in the Sirex transcriptomes were extremely high, indicating that these Minus-C OBPs may be specialized into special OBPs that play a key role in the wasp's olfactory systems. However, the functions of Plus- $\mathrm{C}$ and Minus-C OBPs in insects are not known and need further studies.

\section{Different expression pattern of OBPs in two siricids}

Between two closely related woodwasp species, most genes were found to be orthologous and displayed high sequence similarity $(>90 \%)$ and thus may be related to recognition of common host plants. Interestingly, difference in homologous genes between the two species and between the sexes were also found. SnocOBP3 and SnoCOBP10 was highly expressed in female genitalia and male heads in S. noctilio respectively, while SnitOBP3 and SnitOBP10 did not show obvious tissue bias in $S$. nitobei due to low expression levels. SnocOBP9 and SnitOBP9, which are $P B P$ homologues, were mainly expressed in antennae and thus could be speculated to play a key role in identification of pheromone components. The high expression in both sexes of SnocOBP9 suggested that the protein is used by both sexes to sense sex pheromones or aggregation pheromones. In contrast, SnitOBP9 had a significantly differential expression between the two sexes, which have a higher expression in female antennae, which suggested it is more important for $S$. nitobei females to sense male pheromones. Taken together, different molecular mechanisms between the two closely-related species, and the different roles that the OBPs play between the two sexes are indicated.

\section{Expression pattern of non-antenna specific OBP}

OBPs in the antenna play critical roles in the adaptation of insects to a wide variety of environments and life styles. One of these roles is olfaction, a central aspect of insect life, for example, recognizing sex pheromones or plant volatile components, and guiding normal behaviors such as feeding, mating, or laying egg [39].

Another interesting aspect of OBP research is the study of those members found in other sensory organs in addition to antennae. For example, OBPs and CSPs are identified in structures, such as pheromone glands and reproductive organs, where semiochemicals are delivered. The mandibular glands, in A. mellifera, known to be the site of synthesis and delivery of several pheromones, expressed a variety of OBPs in a caste and age dependent fashion [51]. In the honey bee only nine OBPs are antenna-specific, and the remaining genes are expressed either ubiquitously or are tightly regulated in specialized tissues or during development. In the mosquito Aedes aegypti, OBP22 is expressed in antennae and in male reproductive organs, and is transferred to females during mating $[52,53]$. In some moths, CSP has been reported in pheromone glands [54, 55]. In our study, many OBP genes showed significantly tissuebiased expression, including in antennae, the female genitalia (SnocOBP3, SnocOBP11 and SnitOBP11) or male external genitalia (SnocOBP7 and SnitOBP7), and male heads (SnocOBP10). In a previous report, four $O B P$ s and five CSPs were found in the venom gland proteome of S. noctilio [56]. Through sequence alignment, it was found that the $O B P \mathrm{~s}$ identified in the venom gland were SnocOBP2, SnocOBP6, SnocOBP9, and SnocOBP11, and the CSP identified was SnocCSP25 , indicating that these $O B P$ s and $C S P$ s may play special roles in transport or recognition of chemical signals in venom glands [56]. CSP5 could be a venom gland specific since it was not detected in our antennal 
transcriptomes. An important task in the subsequent research is to understand the other nonolfactory functions of these olfactory proteins.

\section{Olfactory genes located on close loci}

Among the olfactory genes identified in the transcriptomes, we observed that some of the same types of olfactory genes were located on the close loci, such as SnocOBP10 and SnocOBP16, and SnitCSP3 and SnitCSP4. The distances between the two close loci were only $1000 \mathrm{bp}$. In previous studies, it was found that olfactory gene families expand through gene duplication and subsequent evolution [57]. The close loci suggest that these genes share a common ancestor gene and supports the gene duplication model of olfactory gene family expansion.

\section{Number of chemosensory receptor genes varies greatly among different species}

ORco has been observed in Diptera, Lepidoptera, Coleoptera, and Hymenoptera. Compared to traditional odor receptors, ORco is highly conserved, and its homology among insects can reach 50-99\%. Amino acid sequence analysis revealed a highly conserved region at the end of the ORco sequence [31]. In our phylogenetic analysis, we found two genes, SnocORco and SnitORco, that were clustered with the honey bee ORco AmelOR2 [32] and other Hymenoptera ORco, suggesting they could function as a complex with other ORs in the woodwasps as the ORcos in other insects.

At present, in Hymenoptera, most research on chemosensory receptor has focused on the Apocrita, such as the honey bee, $A$. mellifera, $N$. vitripennis, $M$. pulchricornis, M. mediator, Macrocentrus cingulum, Campoletis chlorideae, and ants [50, 58-60]. However, few studies have focused on chemosensation in Symphyta species, only one study identified receptors in wheat stem sawfly [61]. We analyzed a total of 62 and 69 chemosensory genes in S. noctilio and in S. nitobei, respectively, including 41 ORs in S. noctilio and 43 ORs in S. nitobei. The numbers of ORs identified in $S$. noctilio and $S$. nitobei were less than those in most Hymenopteran species, such as M. mediator (60) [36], C. cinctus (72) [61], Chouioia cunea (80) [62], A. mellifera (174) [32], M. pulchricornis (99) [50], N. vitripennis (301) [63], M. cingulum (109) [64], and C. chlorideae (211) [60]. However, the numbers of ORs identified in S. noctilio and S. nitobei were greater than that of some Coleopteran species, such as Anoplophora glabripennis (37), Agrilus planipennis (2), and Monochamus alternatus (9) [65-67]. IRs are a relatively ancestral and conserved receptor family [34, 35]. We identified 13 and 16 IR transcripts in S. noctilio and $S$. nitobei, respectively, similar to the number in $M$. cingulum (13) [64] and C. cunea (10) [62], but less than those in Dipterans, such as D. melanogaster (66) [68, 69]. Our phylogenetic analysis revealed that SnocIR6 and SnitIR6 cluster into a highly conserved IR25a subfamily, and SnocIR4 and SnitIR4 belong to the IR8a family. Therefore, we speculate that IR6 and IR4 are co-receptors of the woodwasps. Similarly, two IRco genes were found in M. mediator [36], while only one IR25a homolog was found in the woodwasp species C. cunea and M. pulchricornis. And we identified a total of 18 GRs ( 8 in S. noctilio and 10 in S. nitobei), which is similar to the number identified in the honey bee but significantly fewer than those in $C$. cinctus (35), N. vitripennis (58), and D. melanogaster (68) $[61,63,70]$.

There are many possible reasons for the differences in olfactory gene number, including sequencing depth. In addition, the physiological state of the woodwasps during sampling may affect gene expression [36, 71]. In addition, we only evaluated antennal transcription, and genes with low expression in other tissues may not be detected. It may also be related to the relative simpler chemical environment and biological habits of Symphyta species than those of social insects and parasitoids [32, 72].

\section{Characteristics and function of chemosensory receptors with biased expression}

ORs with sex-biased expression in siricids was found. Most of antennae-enriched ORs were significantly female-biased and are possibly related to some femalespecific behavior, such as identification of oviposition sites and detection of oviposition substances. However, there are four OR genes (SnocOR18, SnocOR30, SnitOR18, and SnitOR30) were found to be significantly male-biased and their expression levels in the antennae display 10-fold differences between the sexes (Additional file 5), which are possibly related to recognition of pheromones, such as the aggregation pheromone of $S$. noctilio reported [18].

It is worth noting that the expression patterns of most SnocOR30 and SnitOR30 display high homology with AmelOR170. AmelOR170 has shown a biased expression pattern in drone antennae, but the receptor does not bind 9-oxo-2-decenoic acid [73]. Furthermore, none of the investigated woodwasp genes was clustered with AmelOR11, which is the receptor for 9-oxo-2-decenoic acid (9-ODA), the main component of the queen retinue pheromone (QRP) in the honey bee. This result confirms that the olfaction proteins are species specific and different among Hymenoptera due to their wide ecological variations in environment. MmedOR9, which is homologous to SnocOR18 and SnitOR18, is highly and specifically expressed in males, suggesting that these genes may 
play an important role in males such as receiving sex pheromones in Hymenoptera [74].

Expression of trehalose receptors in siricids indicated 2 and 7 sweet receptors in the transcriptomes of S. noctilio and S. nitobei, respectively. Most of these sweet receptors were found to be trehalose receptors. Trehalose is a non-reducing sugar composed of two $\alpha$-glucose molecules joined by an 1,1-glycosidic bond. The sugar is chemically stable and protects plants, plant cells, and plant proteins from freezing and drying. It is a stressresistant protection mechanism. Trehalose is also present in the body fluid of insects and can be used as a energy source for flying. As an important blood sugar in insects, trehalose is present in almost all tissues and organs of insects [75]. Trehalose can influence insects' choice for food via recognition by GRs. Thus, trehalose receptors are important for vital biological processes in insects.

\section{Conclusions}

By examining their antennal transcriptomes, we analyzed 86 and 91 olfactory genes from S. noctilio and S. nitobei, respectively. The number of olfactory genes varies among different species, which may be related to possible reasons, including different olfactory discrimination capabilities based on individual chemical environment and biological habits for different insect species, sequencing depth and sampling status. Most of the olfactory genes identified in two species were homologous between the two species. However, some species-specific olfactory genes were identified from the antennal transcriptomes, which indicated different olfactory molecular mechanisms between the two closely-related species.

Additionally, we verified the expression of 10 SnocOBPs and 10 SnitOBPs in male and female antennae, respectively, thereby confirming the accuracy of our transcriptome data. The high expression of OBPs in antennae supports the function of OBPs in the semiochemical recognition process. Significant tissue-biased or sex-biased expression was observed for many OBP genes, especially those not greatly expressed in the antennae, which suggest OBPs are involved in activities of daily living, for example, recognizing sex pheromones or plant volatile components, and guiding normal behaviors such as feeding, mating, or oviposition. Species-specific expression for several OBP genes may suggest that they strengthened or lost their original function during species reproductive isolation, resulting in olfactory differences between the two species. The olfactory proteins of the siricids were obtained through antennal transcriptome sequencing. However, in order to explore the olfactory mechanisms of the siricids, it is necessary to perform protein expression, fluorescence binding competition, and molecular docking studies.

\section{Methods}

\section{Sample collection and preservation}

$S$. noctilio adults emerge in early July over a period of 2 months and S. nitobei adults emerge in early September, but adult woodwasps only live for 5-12 days [4, 14]. The S. noctilio and S. nitobei woodwasps used in these experiments were collected from Tongliao, Inner Mongolia. Injured wood that exhibited premature aging and teardrop-like flow gum points were selected. The selected woods were cut into 1-m long sections and placed in a net cage while waiting for the wasps to emerge. The wasps were caught immediately after eclosion and time, status, and sex information were recorded. We separated the antennae from the adults and put them in RNA later buffer solution (Invitrogen, Carlsbad, CA, USA). The antennae were stored at $4{ }^{\circ} \mathrm{C}$ for $24 \mathrm{~h}$ and then stored at $-20^{\circ} \mathrm{C}$ or at $-80^{\circ} \mathrm{C}$ for long-term storage at the Forest Conservation Laboratory.

\section{RNA extraction and Illumina transcriptome sequencing}

Total RNA was extracted from adult antennae of both sexes separately (20 antennae each from males and females) using the QIAGEN RNeasy Mini Kit (No. 74134; Qiagen, Hilden, Germany) following the manufacturer's instructions. The RNA concentration was quantified using a NanoDrop 8000 spectrophotometer (Thermo, Waltham, MA, USA). RNA quality was verified using a 2100 Bioanalyzer RNA Nanochip (Agilent, Santa Clara, CA, USA). The high-quality RNA samples (OD260/ $280=1.8-2.2$, OD $260 / 230 \geq 2.0$, RIN $\geq 6.5,28 \mathrm{~S}: 18 \mathrm{~S} \geq 1.0$, $>10 \mu \mathrm{g})$ were placed at $-80^{\circ} \mathrm{C}$ and used to generate cDNA libraries.

The cDNA library construction and Illumina sequencing on the HiSeq 4000 platform were performed at Majorbio Corporation (Shanghai, China). RNA-seq transcriptome libraries were prepared using $5 \mu \mathrm{g}$ of total RNA using the TruSeqTM RNA sample preparation kit from Illumina (San Diego, CA, USA). First, messenger RNA (mRNA) was isolated by oligo (dT) beads according to the poly-A selection, then the mRNA was fragmented to about $300 \mathrm{bp}$ length using fragmentation buffer. Second, the mRNA fragments were reversed to synthesize one-stranded cDNA and double-stranded cDNA using the SuperScript double-stranded cDNA synthesis kit (Invitrogen) with random hexamer primers (Illumina). Next, according to the Illumina library construction plan, the synthesized cDNA was subjected to end-repair, phosphorylation, and ' $\mathrm{A}$ ' base addition. PCR amplification was performed for 15 cycles using Phusion DNA polymerase (New England Biolabs, NEB) for cDNA library enrichment. The cDNA target fragments of 200300 bp were selected using Certified Low Range Ultra Agarose (Bio-Rad) from cDNA library. The cDNA library after fragment selection process was quantified 
using a TBS-380 mini fluorometer, and was subjected to generate clusters by bridge PCR amplification according to quantitative proportions. Finally the cDNA library was sequenced using an Illumina HiSeq 4000 to generate 150 bp paired-end reads.

\section{Assembly and function annotation}

Trimming and quality control of the raw paired-end reads was performed using SeqPrep (https://github.com/ jstjohn/SeqPrep) and Sickle (https://github.com/najoshi/ sickle) to generate clean, high-quality reads. De novo transcriptome assembly was carried out with the short read assembly program Trinity (http://trinityrnaseq. sourceforge.net/) [76]. The consensus cluster sequences and singletons comprise the UniGene dataset. The annotation of unigenes was performed by NCBI BLASTX against a combined database of non-redundant $(\mathrm{Nr})$ String, KEGG, and SwissProt protein sequences with an E-value threshold $<1 \mathrm{e}^{-5}$. The BLAST results were then processed with the Blast2GO program (http://www. blast2go.com/b2ghome) for gene ontology (GO) annotation, which described the function of unigenes, such as their biological processes, molecular functions, and cellular components [77, 78]. The longest ORF for each unigene was determined by the NCBI ORF Finder tool (http://www.ncbi.nlm.nih.gov/gorf/gorf. html). Expression levels are displayed as FPKM values (fragments per kilobase per million reads), which were calculated by RSEM (RNA-Seq by ExpectationMaximization) v1.2.6.

\section{Identification of chemosensory-related genes}

The annotation of olfactory unigenes (OBP, CSP, OR, GR, IR, and SNMP) was performed by searching the $\mathrm{Nr}$ protein database through NCBI BLASTX, with an Evalue threshold $<1 \mathrm{e}-5$. The available protein sequences from Insecta species were used to identify candidate olfaction unigenes in S. noctilio and S. nitobei. Signal P4.0 (http://www.cbs.dtu.dk/services/SignalP/) was used to search for the presence of $\mathrm{N}$-terminal signal peptides in candidate OBP and PBP, and TMHMM server v3.0 (http://www.dk/services/TMHMM/) was used to predict the transmembrane domains of candidate OR, IR, GR and SNMP. After performed amino acid sequence alignment using the Muscle method, phylogenetic trees of olfactory unigenes were constructed using the neighborjoining (NJ) method with the P-distances model and pairwise deletion of gaps in the MEGA v6.0 software package. The sequences used to build the phylogenetic trees included the olfactory genes from $S$. noctilio and $S$. nitobei transcriptomes, and other olfactory genes from other insects by NCBI (Additional file 7). The reliability of the tree structure and node support was evaluated through an analysis of bootstrap with 1000 replicates.
Only bootstrap values $\geq 0.5$ were shown at the corresponding nodes. The lineages with bootstrap values $\geq 0.9$ were labelled with red spots, and bootstrap values between 0.7 and 0.9 were marked with blue spots. The phylogenetic trees were modified with ITOL (https://itol.embl.de/).

\section{Expression analysis by quantitative real-time PCR}

The expression of candidate chemosensory genes was performed using fluorescent quantitative real-time PCR (RT-qPCR). RT-qPCR experiments in S. noctilio and $S$. nitobei were performed separately. Antennae, legs (including the propodium, mesopodium, and metapedes), heads, and external genitals were collected from ten male or ten female adult woodwasps for each biological replicates. Three biological replicates and three technical replicates were used with each qPCR reaction for each tissue to examine reproducibility. Total RNA was extracted following the methods described above and used as template for cDNA synthesis using the PrimeScript RT Reagent Kit with gDNA Eraser (No. RR047A; Takara, Shiga, Japan). Gene-specific primers of the chemosensory genes were designed using Primer3Plus (http://www.primer3plus.com/cgi-bin/dev/primer3plus. cgi) (see Additional file 3).

In order to the accuracy of RT-qPCR, we selected six genes as reference genes from the S.noctilio antennal transcriptome (Actin1, Actin2, Alpha-Tubulin, Beta-Tubulin, TATA Binding protein TBP, Succinate dehydrogenase SDHA). The primers of candidate genes were designed in the same way as chemosensory genes, and the candidate genes were evaluated by GeNorm and Normfinder. GeNorm results indicated that the minimum number of $\beta$-tubulin is within the allowable range, and average expression stability $M$ values of $\beta$-tubulin were less than 0.5 (Additional file 8, Figure S1-S4). Normfinder results showed that Beta-tubulin was the best reference gene in S. noctilio and S. nitobei, which were 0.136 and 0.095, respectively (Additional file 8 , Table S1, S2). These results indicated that Beta-tubulin is a reliable reference gene for both $S$. noctilio and $S$. nitobei for RT-qPCR. Primers for the internal reference gene $(\beta$ tubulin) were listed in the Additional file 6.

PCR analysis was conducted using the Bio-Rad CFX Connect PCR System (Hercules, CA, USA). Each $25 \mu \mathrm{l}$ PCR reaction contained $12.5 \mu$ l of SYBR Premix Ex Taq II (No. RR820A; Takara), $2 \mu$ l of sample cDNA, $1 \mu$ of forward primer $(10 \mathrm{mM}), 1 \mu \mathrm{l}$ of reverse primer $(10 \mathrm{mM})$ and $8.5 \mu \mathrm{l}$ of $\mathrm{dH} 2 \mathrm{O}$ (sterile distilled water). The RTqPCR cycling parameters were as follows: $95^{\circ} \mathrm{C}$ for $30 \mathrm{~s}$; then 40 cycles of $95^{\circ} \mathrm{C}$ for $5 \mathrm{~s}$ and $60^{\circ} \mathrm{C}$ for $30 \mathrm{~s}$; followed by $65^{\circ} \mathrm{C}$ to $95^{\circ} \mathrm{C}$ in increments of $0.5^{\circ} \mathrm{C}$ for $5 \mathrm{~s}$. Each experiment included negative controls without 
template to maintain experimental accuracy. Bio-Rad CFX Manager (version 3.1.1517.0823) was used to normalize expression based on $\Delta \Delta C T$ values, with BetaTubulin as reference gene and the male external genitals samples as control samples. The $2^{-\Delta \Delta}$ CT method was used to generate relative expression values. The comparative analyses for each chemosensory gene among eight tissue samples were assessed using a one-way nested analysis of variance (ANOVA) and the significance analysis was performed with Tukey's honestly significance difference tests in SPSS 21.0.

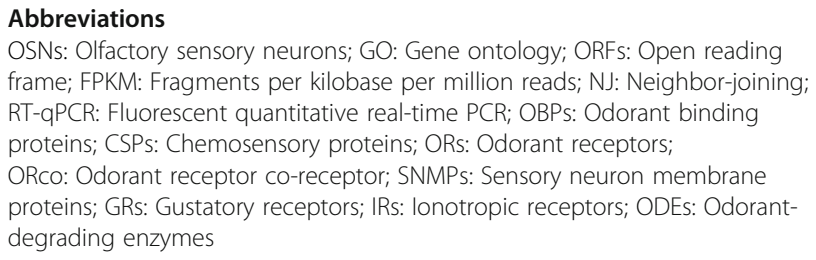

OSNs: Olfactory sensory neurons; GO: Gene ontology; ORFs: Open reading frame; FPKM: Fragments per kilobase per million reads; NJ: Neighbor-joining; RT-qPCR: Fluorescent quantitative real-time PCR; OBPs: Odorant binding proteins; CSPs: Chemosensory proteins; ORs: Odorant receptors; ORco: Odorant receptor co-receptor; SNMPs: Sensory neuron membrane proteins; GRs: Gustatory receptors; IRs: Ionotropic receptors; ODEs: Odorantdegrading enzymes

\section{Supplementary Information}

The online version contains supplementary material available at https://doi. org/10.1186/s12864-021-07452-1.

Additional file 1: Transcriptome information of S. noctilio and S. nitobei. Table S1. Summary of raw reads obtained from S. noctilio and S. nitobei antennal transcriptomes. Table S2. Summary of clean reads obtained from S. noctilio and S. nitobei antennal transcriptomes. Table S3. Assembly statistics for the S. noctilio antennal transcriptome. Table S4. Assembly statistics for the $S$. nitobei antennal transcriptome.

Additional file 2: Best blastX hits for putative odorant binding proteins (OBPs), chemosensory proteins (CSPs), odorant receptors (ORs), sensory neuron membrane proteins (SNMPs), ionotropic receptors (IRs), and gustatory receptors (GRs) of S. noctilio and S. nitobei. (Table S1, Table S2, Table S3, Table S4, Table S5 and Table S6). Table S1. Sequence information and best blasts match information of odorant binding proteins (OBPs). Table S2. Sequence information and best blasts match information of chemosensory proteins (CSPs). Table S3. Sequence information and best blasts match information of odorant receptors (ORs). Table S4. Sequence information and best blasts match information of sensory neuron membrane proteins (SNMPs). Table S5. Sequence information and best blasts match information of gustatory receptors (GRs). Table S6. Sequence information and best blasts match information of ionotropic receptors (IRs).

Additional file 3. The sequence of OBPs with alignment were shown six conserved cysteine residues.

Additional file 4. The sequence of CSPs with alignment were shown four conserved cysteine residues.

Additional file 5. Significance test of The FPKM value of homologous genes (OBPs, CSPs, ORs, SNMPs, GRs and IRs) between two siricid species and male and female. S. noctilio data is colored red and S. nitobei data is colored blue.

Additional file 6. Primers of odorant binding proteins and reference gene for quantitative real-time PCR.

Additional file 7. The OBPs, CSPS, ORs, SNMPs, GRs and IRs of Hymenoptera, Diptera, Lepidoptera, Coleoptera, Blattaria and Orthoptera used in building neighbor-joining phylogenetic trees.

Additional file 8: Selection of reference gene in S. noctilio and S. nitobei Table S1. Normfinder result of the six reference genes in S. noctilio. Table S2. Normfinder result of the six reference genes in S. nitobei. Figure S1. Average expression stability values of remaining control genes in S. noctilio. Figure S2. Determination of the optimal number of control genes for normalization in S. noctilio. Figure S3. Average expression stability values of remaining control genes in S. nitobei. Figure S4. Determination of the optimal number of control genes for normalization in S. nitobei.

\section{Acknowledgements}

We thank Min Bao, Rui Liu for insect collection. We appreciate the proofreading by JJ Scientific Consultant Ltd., UK.

\section{Authors' contributions}

GB collected almost all samples, carried out the molecular genetic studies, performed the sequence alignment, statistical analysis and drafted the manuscript. HE participated in the design of the study, the transcriptome analysis and performed all experiments in revision edition. QH, WJ and WW performed the RT-qPCR and wrote part of the manuscript. ZJ participated in the design of the study and revised the draft of the manuscript. LP proposed the project, designed the whole study, wrote and revised the manuscript. All authors read and approved the final manuscript.

\section{Funding}

This research was supported by the National Natural Science Foundation of China (Grant No. 31570643, 81774015), National Key R\&D Program of China (2017YFD0600103). The funders had no role in study design, data collection and analysis, decision to publish, or preparation of the manuscript.

\section{Availability of data and materials}

All supporting data is included within the article and its additional files. And the transcriptome data were submitted to NCBI, the accession number of $S$. noctilio are from SAMN11338151 to SAMN11338156 and the accession number of S. nitobei are from SAMN11338569 to SAMN11338574. All of the olfactory protein gene sequences were submitted to Genbank, accession number are MK425751- MK425766, MK674426- MK674453 and MK748989MK749121.

\section{Declarations}

\section{Ethics approval and consent to participate}

The woodwasps, S. noctilio and S. nitobei (Hymenoptera: Siricidae) are forestry pests in China, which collections were made with the direct permission of Tongliao forestry bureau. They are not included in the "List of Endangered and Protected Animals in China". All operations were performed according to ethical guidelines in order to minimize pain and discomfort to the insects.

\section{Consent for publication}

Not applicable.

\section{Competing interests}

The authors declare that they have no competing interests.

\section{Author details}

${ }^{1}$ The Key Laboratory for Silviculture and Conservation of the Ministry of Education, School of Forestry, Beijing Forestry University, 35 Qinghua Dong Road, Haidian District, Beijing 100083, People's Republic of China. ${ }^{2}$ Institute of Medicinal Plant Development, Chinese Academy of Medical Sciences and Peking Union Medical College, Beijing 100193, People's Republic of China.

Received: 11 February 2020 Accepted: 19 February 2021

Published online: 10 March 2021

\section{References}

1. Talbot PHB. The Sirex-Amylostereum-Pinus association. Annu Rev Phytopathol. 1977;15:41-54.

2. Benson RB. Studies in Siricidae, especially of Europe and southern Asia (Hymenoptera, Symphyta). Bull Entomol Res. 1943;34:27-51.

3. Taylor KL. The Sirex woodwasp: ecology and control of an introduced forest insect. Australia: CSIRO; 1981

4. Neumann FG, Morey JL, McKimm RJ. The Sirex wasp in Victoria. BulletinDepartment of Conservation, Forests and Lands, Victoria, vol. 29; 1987. p. 41.

5. Morgan FD, Stewart NC. The biology and behavior of the wood-wasp Sirex noctilio F. in New Zealand. Transact R Soc Newland. 1966;7(14):195-204. 
6. Coutts MP. Rapid physiological change in Pinus radiata following attack by Sirex noctilio and its associated fungus, Amylostereum sp. Aust J Sci. 1968; 30(5):275-7.

7. Bordeaux JM, Dean JFD. Susceptibility and Response of Pines to Sirex noctilio. In: Slippers B, de Groot P, Wingfield MJ, editors. The Sirex Woodwasp and its Fungal Symbiont: Research and Management of a Worldwide Invasive Pest. Dordrecht: Springer; 2012. p. 31-50.

8. Coutts MP, Dolezal J. Some effects of bark cincturing on the physiology of Pinus radiata, and on Sirex attack. Aust Forest Res. 1966;2:17-28.

9. Zylstra KE, Dodds KJ, Francese JA, Mastro V. Sirex noctilio in North America: the effect of stem-injection timing on the attractiveness and suitability of trap trees. Agr Forest Entomol. 2010;12(3):243-50.

10. Hurley BP, Slippers B, Wingfield MJ. A comparison of control results for the alien invasive woodwasp, Sirex noctilio, in the southern hemisphere. Agr Forest Entomol. 2007;9(3):159-71.

11. Li DP, Shi J, Luo YQ. Mutualism between the Eurasian woodwasp, Sirex noctilio (Hymenoptera: Siricidae) and its fungal symbiont Amylostereum areolatum (Russulales: Amylostereaceae). Acta Entomol Sin. 2015;58(9): 1019-29.

12. Du WG, Jiao JW, Wang QY. Brief report on luring and collecting Sirex nitobei by trap log. Heilongjiang Agric Sci. 2011;5:57-8.

13. Xiao GR, Wu J. The Siricid wood wasps of China (Hymenoptera, Symphyta). Sci Silva Sin. 1983;19(zj):1-29.

14. Wang $M$, Bao $M, A o T G$, Ren LL, Luo YQ. Population distribution patterns and ecological niches of two Sirex species damaging Pinus sylvestris var. mongolica. Chin J Appl Entomol. 2017;54(6):924-32.

15. Dodds KJ, Zylstra KE, Dubois GD, Hoebeke ER. Arboreal insects associated with herbicide-stressed Pinus resinosa and Pinus sylvestris used as Sirex noctilio trap trees in New York. Environ Entomol. 2012a. https://doi.org/10.1 603/EN12180

16. Dodds KJ, de Groot P. Sirex, Surveys and Management: Challenges of having Sirex noctilio in North America. In: Slippers B, de Groot P, Wingfield MJ, editors. The Sirex Woodwasp and its Fungal Symbiont: Research and Management of a Worldwide Invasive Pest. Dordrecht: Springer; 2012b. p. 265-86.

17. Böröczky K, Crook DJ, Jones TH, Kenny JC, Zylstra KE, Mastro VC, et al. Monoalkenes as Contact Sex Pheromone Components of the Woodwasp Sirex noctilio. J Chem Ecol. 2009. https://doi.org/10.1007/s10886-009-9693-6.

18. Cooperband MF, Böröczky K, Hartness A, Jones TH, Zylstra KE, Tumlinson JH, et al. Male-produced pheromone in the European Woodwasp, Sirex noctilio. J Chem Ecol. 2012. https://doi.org/10.1007/s10886-012-0060-7.

19. Liu R. Identification of pheromone components of Sirex noctilio Fabricius and trapping technology in forest. Dissertation: Beijing Forestry University. Beijing; 2019.

20. Pilpel $Y$, Lancet $D$. The variable and conserved interfaces of modeled olfactory receptor proteins. Protein Sci. 1999;8(5):969-77.

21. Zacharuk RY. Ultrastructure and function of insect Chemosensilla. Annu Rev Entomol. 1980;25(1):27-47.

22. Steinbrecht RA. Pore structures in insect olfactory sensilla: a review of data and concepts. Int J Insect Morphol Embryo. 1997;26(3-4):229-45.

23. Leal WS. Pheromone reception. In: Schulz S, editor. The Chemistry of Pheromones and Other Semiochemicals II. Berlin: Springer; 2005. p. 1-36.

24. Leal WS. Odorant reception in insects: roles of receptors, binding proteins, and degrading enzymes. Annu Rev Entomol. 2013. https://doi.org/10.1146/a nnurev-ento-120811-153635.

25. Benton R, Sachse S, Michnick SW, Vosshall LB. Atypical membrane topology and Heteromeric function of Drosophila odorant receptors in vivo. PLoS Biol. 2006. https://doi.org/10.1371/journal.pbio.0040020.

26. Wicher D, Schäfer R, Bauernfeind R, Stensmyr MC, Heller R, Heinemann SH, et al. Drosophila odorant receptors are both ligand-gated and cyclic-nucleotide-activated cation channels. Nature. 2008. https://doi.org/10.1038/nature06861.

27. Raming K, Krieger J, Strotmann J, Boekhoff I, Kubick S, Baumstark C, et al. Cloning and expression of odorant receptors. Nature. 1993. https://doi.org/1 $0.1038 / 361353 a 0$.

28. Ishida Y, Leal WS. Rapid inactivation of a moth pheromone. Proc Natl Acad Sci U S A. 2005;102(39):14075-9.

29. Durand N, Carot-Sans G, Bozzolan F, Rosell G, Siaussat D, Debernard S, et al. Degradation of pheromone and plant volatile components by a same odorant-degrading enzyme in the cotton leafworm, Spodoptera littoralis. PLoS One. 2011. https://doi.org/10.1371/journal.pone.0029147.

30. Zhang J, Wang B, Dong S, Cao D, Dong J, Walker WB, et al. Antennal transcriptome analysis and comparison of chemosensory gene families in two closely related noctuidae moths, Helicoverpa armigera and $H$. assulta. PLoS One. 2015;10(2):e0117054.

31. Lundin C, Käll L, Kreher SA, Kapp K, Sonnhammer EL, Carlson JR, et al. Membrane topology of the Drosophila OR83b odorant receptor. FEBS Lett. 2007;581(29):5601-4.

32. Robertson HM, Wanner KW. The chemoreceptor superfamily in the honey bee Apis mellifera: expansion of the odorant, but not gustatory, receptor family. Genome Res. 2006;16(11):1395-403.

33. Abuin L, Bargeton B, Ulbrich MH, Isacoff EY, Kellenberger S, Benton R. Functional architecture of olfactory ionotropic glutamate receptors. Neuron. 2011;69(1):44-60.

34. Wang YL, Chen Q, Zhao HB, Ren BZ. Identification and comparison of candidate olfactory genes in the olfactory and non-olfactory organs of elm Pest Ambrostoma quadriimpressum (Coleoptera: Chrysomelidae) based on Transcriptome analysis. PLoS One. 2016;11(1):e0147144.

35. Wang YL, Chen Q, Guo JQ, Li J, Wang JT, Wen M, Zhao HB, Ren BZ. Molecular basis of peripheral olfactory sensing during oviposition in the behavior of the parasitic wasp Anastatus japonicus. Insect Biochem Mol Biol. 2017:89:58-70.

36. Wang SN, Peng Y, Lu ZY, Dhiloo KH, Gu SH, Li RJ, et al. Identification and expression analysis of putative chemosensory receptor genes in Microplitis mediator by antennal transcriptome screening. Int J Biol Sci. 2015;11:737.

37. Hekmat-Scafe DS, Scafe CR, McKinney AJ, Tanouye MA. Genome-wide analysis of the odorant-binding protein gene family in Drosophila melanogaster. Genome Res. 2002;12(9):1357-69.

38. Vogt RG. Biochemical diversity of odor detection: OBPs, ODEs and SNMPs. Insect Pheromone Biochemistry \& Molecular Biology. In: Blomquist IG, Vogt RG, editors. . London: Academic; 2003. p. 391-445.

39. Forêt S, Maleszka R. Function and evolution of a gene family encoding odorant binding-like proteins in a social insect, the honey bee (Apis mellifera). Genome Res. 2006;16(11):1404-13.

40. Xu PX, Zwiebel LJ, Smith DP. Identification of a distinct family of genes encoding atypical odorant-binding proteins in the malaria vector mosquito, Anopheles gambiae. Insect Mol Biol. 2003;12(6):549-60.

41. Gong DP, Zhang HJ, Zhao P, Xia QY, Xiang ZH. The odorant binding protein gene family from the genome of silkworm, Bombyx mori. BMC Genomics. 2009. https://doi.org/10.1186/1471-2164-10-332.

42. Vieira FG, Forêt $\mathrm{S}$, He XL, Rozas J, Field LM, Zhou JJ. Unique features of odorant-binding proteins of the parasitoid wasp Nasonia vitripennis revealed by genome annotation and comparative analyses. PLoS One. 2012;7(8):e43034

43. Nie XP, Li QL, Xu C, Li DZ, Zhang Z, Wang MQ, et al. Antennal transcriptome and odorant binding protein expression profiles of an invasive mealybug and its parasitoid. J Appl Entomol. 2017;142:149-61.

44. Yin XW, lovinella I, Marangoni R, Cattonaro F, Flamini G, Sagona S, et al. Odorant-binding proteins and olfactory coding in the solitary bee Osmia cornuta. Cell Mol Life Sci. 2013;70(16):3029-39.

45. Wang N, Wang NX, Niu LM, Bian SN, Xiao JH, Huang DW. Odorant-binding protein (OBP) genes affect host specificity in a fig-pollinator mutualistic system. Insect Mol Biol. 2014;23(5):621-31.

46. Zhang S, Zhang YJ, Su HH, Gao XW, Guo YY. Identification and expression pattern of putative odorant-binding proteins and chemosensory proteins in antennae of the Microplitis mediator (Hymenoptera: Braconidae). Chem Senses. 2009;34(6):503-12.

47. Kirkness EF, Haas BJ, Sun WL, Braig HR, Perotti MA, Clark JM, et al. Genome sequences of the human body louse and its primary endosymbiont provide insights into the permanent parasitic lifestyle. PNAS. 2010;107(27):12168-73.

48. Zhou JJ. Odorant-binding protein in insect. Vitam Horm. 2010;83:241-72.

49. Wang JZ, Hu P, Gao P, Tao J, Luo YQ. Antennal transcriptome analysis and expression profiles of olfactory genes in Anoplophora chinensis. Sci Rep. 2017. https://doi.org/10.1038/s41598-017-15425-2.

50. Sheng S, Liao CW, Zheng Y, Zhou Y, Xu Y, Song WM, et al. Candidate chemosensory genes identified in the endoparasitoid Meteorus pulchricornis (Hymenoptera: Braconidae) by antennal transcriptome analysis. Comp Biochem Physiol Part D Genomics Proteomics. 2017;22:20-31.

51. Iovinella I, Dani FR, Niccolini A, Sagona S, Michelucci E, et al. Differential expression of odorant-binding proteins in the mandibular glands of the honey bee according to caste and age. J Prot Res. 2011;10:3439-49.

52. Li S, Picimbon JF, Ji SD, Kan YC, Qiao CL, et al. Multiple functions of an odorant-binding protein in the mosquito Aedes aegypti. Biochem Biophys Res Comm. 2008;372(3):464-8. 
53. Sirot LK, Poulson RL, Mckenna MC, Girnary H, Wolfner MF, Harrington LC Identity and tranfer of male reproductive gland proteins of the dengue vector mosquito, Aedes aegypti: potential tools for control of female feeding and reproduction. Insect Biochem Mol Biol. 2008;38:176-89.

54. Jacquin-Joly E, Vogt RG, Francois MC, Nagnan-Le MP. Functional and expression pattern analysis of chemosensory proteins expressed in antennae and pheromonal gland of Mamestra brassicae. Chem Senses. 2001:26:833-44.

55. Dani FR, Michelucci E, Francese S, Mastrobuoni G, Cappellozza S, Marca GL, et al. Odorant-binding proteins and chemosensory proteins in pheromone detection and release in the silkmoth Bombyx mori. Chem Senses. 2011; 36(4):335-44.

56. Wang $T$, Zhao M, Rotgans BA, Ni G, Dean JF, Nahrung HF, et al. Proteomic analysis of the venom and venom sac of the woodwasp, Sirex noctilio towards understanding its biological impact. J Proteome. 2016;146:195-206.

57. Kucharski R, Maleszka J, Maleszka R. A possible role of DNA methylation in functional divergence of a fast evolving duplicate gene encoding odorant binding protein 11 in the honeybee. Proc Biol Sci. 2016. https://doi.org/10.1 098/rspb.2016.0558.

58. Werren JH, Richards S, Desjardins CA, Niehuis O, Gadau J, Colbourne JK, et al. Functional and evolutionary insights from the genomes of three parasitoid Nasonia species. Science. 2010;327:343-8.

59. Ahmed T, Zhang TT, Wang ZY, He KL, Bai SX. Identification and expression pattern analysis of chemosensory receptor genes in the Macrocentrus cingulum (Hymenoptera: Braconidae) antennae. Eur J Entomol. 2016;113:76.

60. Sun YL, Dong JF, Ning C, Ding PP, Huang LQ, Sun JG, et al. An odorant receptor mediates the attractiveness of cis-jasmone to Campoletis chlorideae, the endoparasitoid of Helicoverpa armigera. Insect Mol Biol. 2019; 28:23-34.

61. Robertson HM, Waterhouse RM, Walden KK, Ruzzante L, Reijnders MJ, Coates BS, et al. Genome sequence of the wheat stem sawfly, Cephus cinctus, representing an early-branching lineage of the hymenoptera, illuminates evolution of hymenopteran chemoreceptors. Genome Biol. Evol. 2018;10(11):2997-3011

62. Zhao Y, Wang F, Zhang X, Zhang S, Guo S, Zhu G, et al. Transcriptome and expression patterns of chemosensory genes in antennae of the parasitoid wasp Chouioia cunea. PLoS One. 2016;11:e0148159.

63. Robertson HM, Gadau J, Wanner KW. The insect chemoreceptor superfamily of the parasitoid jewel wasp Nasonia vitripennis. Insect Mol Biol. 2010;19: 121-36

64. Ahmed T, Zhang T, Wang Z, He K, Bai S. Gene set of chemosensory receptors in the polyembryonic endoparasitoid Macrocentrus cingulum. Sci Rep. 2016;6:24078.

65. Hu P, Wang J, Cui M, Tao J, Luo Y. Antennal transcriptome analysis of the asian longhorned beetle Anoplophora glabripennis. Sci Rep. 2016;6:26652.

66. Wang J, Li DZ, Min SF, Mi F, Zhou SS, Wang MQ. Analysis of chemosensory gene families in the beetle Monochamus alternatus and its parasitoid Dastarcus helophoroides. Comp Biochem Physiol D-Genomics Proteomics. 2014;11:1-8

67. Mamidala P, Wijeratne AJ, Wijeratne S, Poland T, Qazi SS, Doucet D, et al. Identification of odor-processing genes in the emerald ash borer, Agrilus planipennis. PLOS One. 2013:8:1-15.

68. Benton R, Vannice KS, Gomez-Diaz C, Vosshall LB. Variant ionotropic glutamate receptors as chemosensory receptors in Drosophila. Cell. 2009;136:149-62.

69. Croset $\mathrm{V}$, Rytz R, Cummins SF, Budd A, Brawand D, Kaessmann H, et al. Ancient protostome origin of chemosensory lonotropic glutamate receptors and the evolution of insect taste and olfaction. PLoS Genet. 2010. https:// doi.org/10.1371/journal.pgen.1001064.

70. Scott K, Brady R, Cravchik A, Morozov P, Rzhetsky A, Zuker C, et al. A chemosensory gene family encoding candidate gustatory and olfactory receptors in Drosophila. Cell. 2001;104:661-73.

71. Gu SH, Zhou JJ, Gao S, Wang DH, Li XC, Guo YY, et al. Identification and comparative expression analysis of odorant binding protein genes in the tobacco cutworm Spodoptera litura. Sci Rep. 2015;5:13800.

72. Goldman-Huertas B, Mitchell RF, Lapoint RT, Faucher CP, Hildebrand JG, Whiteman NK. Evolution of herbivory in Drosophilidae linked to loss of behaviors, antennal responses, odorant receptors, and ancestral diet. Proc Natl Acad Sci U S A. 2015;112:3026-31.

73. Wanner KW, Nichols AS, Walden KK, Brockmann A, Luetje CW, Robertson HM. A honey bee odorant receptor for the queen substance 9-oxo-2decenoic acid. Proc Natl Acad Sci U S A. 2007;104(36):14383-8.
74. Ma L, Gu SH, Liu ZW, Wang SN, Guo YY, Zhou JJ, et al. Molecular characterization and expression profiles of olfactory receptor genes in the parasitic wasp, Microplitis mediator (Hymenoptera: Braconidae). J Insect Physiol. 2014;60:118-26.

75. Wyatt GR. The biochemistry of sugars and polysaccharides in insects. Adv Insect Physiol. 1967;4:287-360.

76. Grabherr MG, Haas BJ, Yassour M, Levin JZ, Thompson DA, Amit I, et al. Fulllength transcriptome assembly from RNA-Seq data without a reference genome. Nat Biotechnol. 2011;29(7):644-52.

77. Conesa A, Götz S, García-Gómez JM, Terol J, Talón M, Robles M. Blast2GO: a universal tool for annotation, visualization and analysis in functional genomics research. Bioinformatics. 2005;21(18):3674-6.

78. Hu P, Tao J, Cui MM, Gao CL, Lu PF, Luo YQ. Antennal transcriptome analysis and expression profiles of odorant binding proteins in Eogystia hippophaecolus (Lepidoptera: Cossidae). BMC Genomics. 2016;17:651.

\section{Publisher's Note}

Springer Nature remains neutral with regard to jurisdictional claims in published maps and institutional affiliations.

Ready to submit your research? Choose BMC and benefit from

- fast, convenient online submission

- thorough peer review by experienced researchers in your field

- rapid publication on acceptance

- support for research data, including large and complex data types

- gold Open Access which fosters wider collaboration and increased citations

- maximum visibility for your research: over $100 \mathrm{M}$ website views per year

At BMC, research is always in progress.

Learn more biomedcentral.com/submissions 